\title{
An Assessment of the Icing Blade and the SEA Multi-Element Sensor for Liquid Water Content Calibration of the NASA GRC Icing Research Tunnel
}

\author{
Laura E. Steen ${ }^{1}$ and Robert F. Ide ${ }^{2}$ \\ HX5 Sierra, Cleveland, OH, 44135 \\ and \\ Judith Foss Van Zante ${ }^{3}$ \\ NASA Glenn Research Center, Cleveland, $\mathrm{OH}, 44135$
}

The Icing Research Tunnel at NASA Glenn has recently switched from using the Icing Blade to using the SEA Multi-Element Sensor (also known as the multi-wire) for its calibration of cloud liquid water content. In order to peform this transition, tests were completed to compare the Multi-Element Sensor to the Icing Blade, particularly with respect to liquid water content, airspeed, and drop size. The two instruments were found to compare well for the majority of Appendix $\mathrm{C}$ conditions. However, it was discovered that the Icing Blade undermeasures when the conditions approach the Ludlam Limit. This paper also describes data processing procedures for the Multi-Element Sensor in the IRT, including collision efficiency corrections, mounting underneath a splitter plate, and correcting for a jump in the compensation wire power. Further data is presented to describe the repeatability of the IRT with the Multi-Element Sensor, health-monitoring checks for the instrument, and a sensingelement configuration comparison. Ultimately these tests showed that in the IRT, the multiwire is a better instrument for measuring cloud liquid water content than the blade.

\section{Nomenclature}

$C=$ heat capacity of water (equal to $1.0 \mathrm{cal} / \mathrm{g}$ )

$d \quad=$ thickness of ice accreted onto the Icing Blade, in $\mathrm{mm}$

$E_{b} \quad=$ collision efficiency for the Icing Blade (also frequently called the collection efficiency)

$E_{H P} \quad=$ collision efficiency of the half-pipe in the Multi-Element sensor (also frequently called the collection efficiency)

GRC $=$ (NASA) Glenn Research Center

IRT $\quad=$ Icing Research Tunnel

$L_{\text {evap }}=$ latent heat of evaporation for liquid water, in cal $/ \mathrm{g}$

LWC $=$ Liquid Water Content, in $\mathrm{g} / \mathrm{m}^{3}$

MVD $=$ median volumetric diameter, in $\mu \mathrm{m}$

$l_{\text {sense }} \quad=$ length of sensing element, in $\mathrm{mm}$

$P_{\text {comp }}=$ power output for the compensation wire, in watts

$P_{d r y} \quad=$ sensing element power attributed to surrounding ambient (non-liquid/ice water) conditions, in watts

$P_{\text {elem }}=$ power output for a vertical sensing element, in watts

$P_{\text {total }}=$ total power output for a given sensing element, in watts

$P_{\text {wet }} \quad=$ sensing element power output that is attributed to the evaporation of liquid or ice water, in watts

$S_{\text {vol }} \quad=$ sample volume of sensing element

${ }^{1}$ Icing Cloud Calibration Engineer, Test Engineering Services, 21000 Brookpark Road, MS 6-8, AIAA Member

${ }^{2}$ Icing Subject Matter Expert, Test Engineering Services, 21000 Brookpark Road, MS 6-8

${ }^{3}$ Technical Lead: Icing, Facilities Division, 21000 Brookpark Road, MS 6-2, AIAA Senior Member

American Institute of Aeronautics and Astronautics 
$t \quad=$ spray time, in seconds

$T_{\text {ambient }}=$ ambient (static) air temperature

$T_{\text {evap }} \quad=$ evaporative temperature of water (function of static air pressure)

TAS = True Airspeed, in $\mathrm{m} / \mathrm{s}$

TWC $=$ Total Water Content: measured by the forward-facing half-pipe sensing element

$V \quad=$ Tunnel Airspeed, in knots

$w_{\text {sense }}=$ width of sensing element

\section{Introduction}

$\mathrm{T}$

HE Icing Research Tunnel (IRT) at NASA Glenn Research Center (GRC) is considered one of the leading facilities in the world for studying aircraft icing and certifying aircraft to fly in icing conditions. The icing cloud that is created in the IRT is calibrated regularly, which includes the cloud uniformity, drop size distributions, and liquid water content (LWC) of the cloud. A poor determination of the cloud LWC (particularly an over-estimate) could result in inadvertent certification of an ice protection system that cannot handle the full amount of water loading that it may encounter in flight.

For any given test facility, if there is a change in calibration instrumentation, a thorough analysis must be done to ensure that the information is accurate. A direct correlation between the instruments must be established that spans the full range of expected test conditions. If the facility calibration changes, it must be established whether these changes are due to changes in the facility itself or to changes in the instrumentation. Calibration changes due to instrumentation are generally indicated by a disagreement between the new instrument and the old instrument. If this happens, it must be accompanied by a rigorous analysis of the data and the principles that may have caused the change, so that either the new instrument or the old instrument may be trusted. In recent years, as part of our effort to continually improve the IRT's calibration instrumentation, the IRT staff have transitioned from using the Icing Blade to the Multi-Element sensor for liquid water content calibration. Rigorous analysis of the two instruments has been done, including a direct comparison of the instruments that spans the full range of expected test conditions and an assessment of the capabilities and limitations of each.

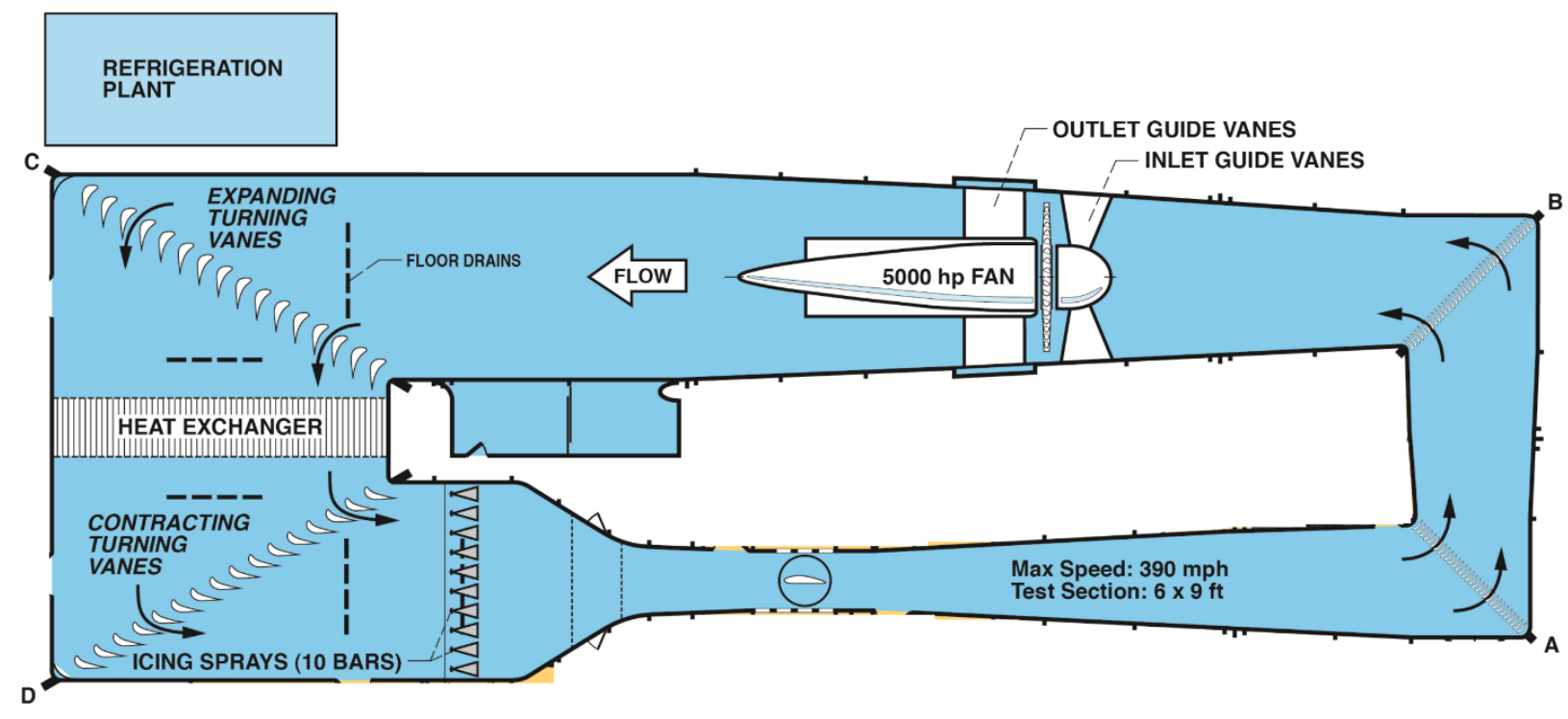

CD-10-83244c

Figure 1. A plan view schematic of the Icing Research Tunnel.

\section{NASA Glenn Icing Research Tunnel}

All test data presented in this report were taken in the NASA Glenn Icing Research Tunnel. The IRT is a closed-

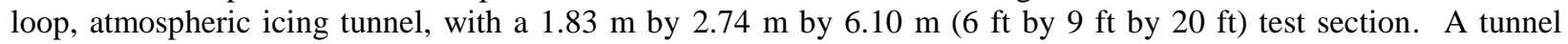
schematic is shown in Fig. 1. The IRT's calibrated test section speed ranges between 50 and 350 knots. The test section temperature can be controlled between $+10{ }^{\circ} \mathrm{C}$ total temperature to $-35{ }^{\circ} \mathrm{C}$ static temperature. Drop sizes in

American Institute of Aeronautics and Astronautics 
the IRT are described in terms of median volumetric diameter (MVD), which is the drop diameter at which half the liquid water content volume is contained in smaller drops (and half in larger drops). All water supplied to the IRT spray bars has been filtered and de-ionized. There are two types of nozzles mounted in the spraybars: the Standard nozzles that have a higher water flow rate, and the Mod1 nozzles that have a lower water flow rate. Currently, there are 165 Standard nozzles and 88 Mod1 nozzles in the spray bars. These air-atomizing spray nozzles can produce a cloud with drop-size distributions with a calibrated MVD between 14 and $270 \mu \mathrm{m}$, with diameters as high as 1200 $\mu \mathrm{m}$. The calibrated LWC range of the IRT is between 0.2 and $4.5 \mathrm{~g} / \mathrm{m}^{3}$, dependent on tunnel airspeed. Nozzle air pressure and water pressure and nozzle type are used to create the desired MVD and LWC. A full report on the cloud calibration of the IRT can be found in Ref. 1. The results of the aero-thermal calibration of the IRT are reported in Ref. 2.

\section{The SEA Multi-Element Sensor}

\section{A. Instrument Description}

The Multi-Element sensor, often called the multi-wire, and its data processing system were developed by Science Engineering Associates, Inc. (SEA). A typical multi-element sensor is shown in Fig. 2a. The sensing elements are

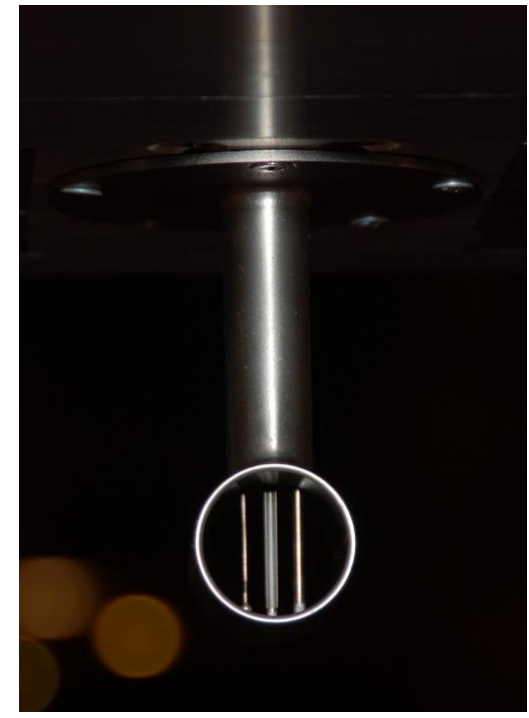

a) Multi-wire mounted in the Icing Research Tunnel

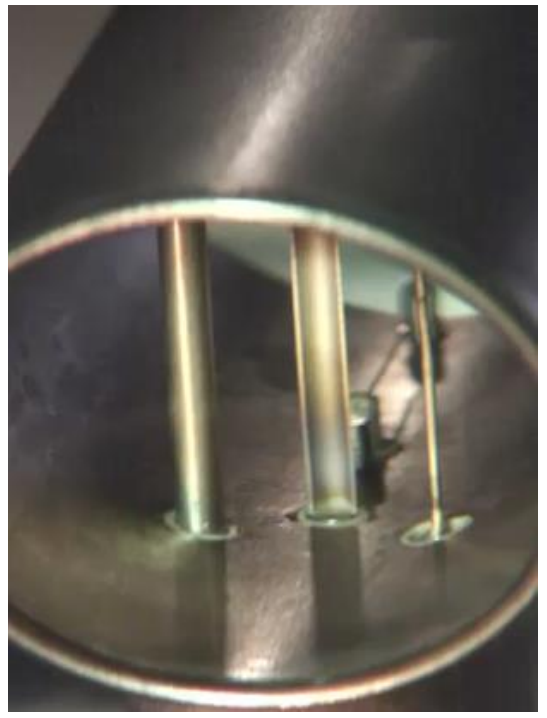

b) Close-up of the multi-wire sensing elements

Figure 2. The Multi-wire liquid water content instrument, SN 2022. The sensing elements of the Multi-wire, as they are shown in (b) are the 2.1-mm hollow cylinder (left), the 2.1-mm diameter forward facing half-pipe (center), the $0.5-\mathrm{mm}$ wire (right), and the compensation wire (behind). positioned inside a heated shroud that is approximately $25.4 \mathrm{~mm}$ in diameter. A typical multielement shroud contains three sensing elements of various sizes, as well as a compensation wire. The elements shown in Fig. 2b are a $2.1 \mathrm{~mm}$ diameter hollow cylinder, $2.1 \mathrm{~mm}$ diameter forward-facing half-pipe (Total Water Content, or TWC element), and a $0.5 \mathrm{~mm}$ diameter wire. A compensation wire is located behind the central element, parallel to the shroud. The compensation wire (or "comp wire") is intended to compensate for changes in atmospheric (dry) conditions. Newer multi-element sensors employ a $2.1 \mathrm{~mm}$ diameter rearfacing half-pipe element in place of the hollow cylinder element. Single-element sensors are also available that contain only one sensing element and the compensation wire.

\section{B. Theory of Operation}

The theory of operation for the multi-element sensor is described here based on the information in the SEA User's Manual $^{3}$. This report gives an abbreviated version from that text that is more targeted to the authors' primary purposes, namely wind tunnel testing.

The multi-element sensor works like a constant temperature anemometer. A voltage is applied across each of the sensing elements, and the elements are maintained at a constant temperature of $140{ }^{\circ} \mathrm{C}$. As the sensor encounters airflow and impinging water, the data system records the total amount of power that is required to maintain each element at a constant temperature. The main sensing element(s) are mounted perpendicular to the flow. The total power $\left(P_{\text {total }}\right)$ required to maintain these elements at a constant temperature includes both $P_{\text {wet }}$ and $P_{d r y} . P_{\text {wet }}$ is the power required to warm and evaporate impinging water, and $P_{d r y}$ is the amount of power required to overcome all cooling influences except for water: namely, the surrounding airflow. Thus, $P_{\text {elem,total }}=P_{\text {elem, wet }}+P_{\text {elem,dry }}$. Additionally, a compensation wire is mounted behind the sensing elements, parallel to the flow. The compensation 
wire is mounted to be shielded from the water drops, so its cooling influences are airspeed, air temperature, and relative humidity $\left(P_{\text {comp,total }}=P_{\text {comp }, d r y}=P_{\text {comp }}\right)$. The total power measured by each of the other sensing elements $P_{\text {elem,dry }}$ is directly correlated to the compensation wire, $P_{\text {comp,total }}$. SEA calibrates each element to determine this correlation in the following terms:

$$
P_{\text {elem }, \text { wet }}=P_{\text {elem }, \text { total }}-\left(\text { offset }+ \text { slope } * P_{\text {comp }}\right)
$$

Any changes to the compensation wire power will be reflected in the wet power of the sensing elements, and therefore in the calculated LWC during a spray. Pre-spray (dry air) liquid water content values are zeroed (tared) through the data system before each spray so that the correct measured liquid water content is displayed.

After the dry power term has been subtracted from the measurements, the wet power term must be converted into liquid water content. The wet power includes the power required to heat the liquid water to its evaporative temperature as well as the power required to evaporate the liquid water (latent heat of evaporation). In considering the evaporation of water at an ambient temperature, the amount of energy (heat) required (in calories per gram) can be written as:

$$
C\left(T_{\text {evap }}-T_{\text {ambient }}\right)+L_{\text {evap }}
$$

Where Levap is the latent heat of evaporation (cal $/ \mathrm{g}) ; T_{\text {evap }}$ is the evaporative temperature of water $\left({ }^{\circ} \mathrm{C}\right)$. Both $L$ evap and $T_{\text {evap }}$ are a function of the static air pressure. $T_{\text {ambient }}$ is the initial temperature of the water $\left({ }^{\circ} \mathrm{C}\right)$, which is assumed to be the same temperature as the static temperature of the air. The constant coefficient $C$ is the heat capacity of water, or the amount of energy required to raise the temperature of water by $1{ }^{\circ} \mathrm{C}$, which is equal to $1.0 \mathrm{cal} / \mathrm{g}$.

In order to convert the amount of evaporated water $(\mathrm{g})$ into liquid water content, $\left(\mathrm{g} / \mathrm{m}^{3}\right)$ the sample volume of the sensing element must be known. This is calculated by the following equation:

$$
S_{\text {vol }}=l_{\text {sense }} \cdot w_{\text {sense }} \cdot T A S
$$

where $S_{V o l}$ is the volume of air sampled per unit time, $I_{\text {sense }}$ and $w_{\text {sense }}$ are the length and width of the sense element, and TAS is the true airspeed. Lastly, all these terms are multiplied by a constant to account for the necessary unit conversions, and the equation for calculating liquid water content is therefore:

$$
L W C=\frac{P_{\text {sense,wet }} \cdot 2.389 \times 10^{5}}{\left[L_{\text {evap }}+C\left(T_{\text {evap }}-T_{\text {ambient }}\right)\right] \cdot T A S \cdot l_{\text {sense }} \cdot W_{\text {sense }}}
$$

This calculation, from Science Engineering Associates ${ }^{3}$, accounts only for measurements of liquid water content. In the presence of ice, the calculations must account for the latent heat of fusion and the latent heat of evaporation.

\section{Multi-Element Sensor Test Setup: Splitter Plate Mount}

For all test results presented in this report, the multi-element sensor was mounted from the test section ceiling, positioned at vertical and horizontal centerline over the center of the test section turntable.

During testing in the IRT it was found that the $88.4 \mathrm{~mm}$ (3.48 in)-thick mounting structure caused local flow angularity which created non-uniform flow at the sensor location. This was made clear by spraying a cloud of supercooled liquid water at an unheated (sensors and deice turned off) multi-wire head and allowing ice to accumulate on the sensing elements. The ice accumulated evenly except for a thin (approx. 1mm) region near the top of the sensing elements, closest to the strut, which had no ice buildup (Fig. 3a). Note that the shadow region is on the side of the shroud that contains the compensation wire. A substantial shadow could cause the comp wire to read too low, artificially increasing the LWC value. However, if the vertical sensing element was substantially shadowed, that could in turn artificially decrease the LWC value. Note that Fig. 3a also shows a thicker buildup of ice seen at the opposite end of some sensing elements. To correct this problem in flow angularity, a splitter plate with a beveled heated front edge was mounted between the support and the multi-element sensor. The aforementioned test was run again at the same conditions except at a colder total temperature $\left(-17^{\circ} \mathrm{C}\right.$ instead of $\left.-10^{\circ} \mathrm{C}\right)$, and the sensor showed uniform icing of the three elements (Fig. 3b). Additional tests were completed using a $203.2 \mathrm{~mm}$ long, $6.35 \mathrm{~mm}$ diameter rod mounted in the center of the test section. Two sets of tests were completed: one with the rod mounted underneath a splitter plate, and one with the rod mounted directly on the 88.4-mm-thick mounting structure normally used for the

American Institute of Aeronautics and Astronautics 


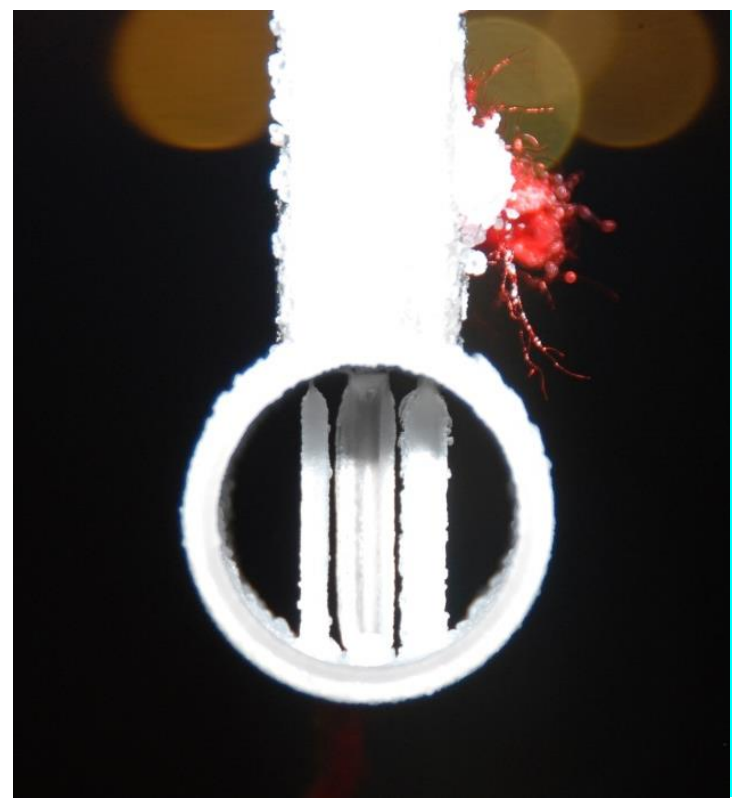

a) Multi-wire on mounting strut, no splitter

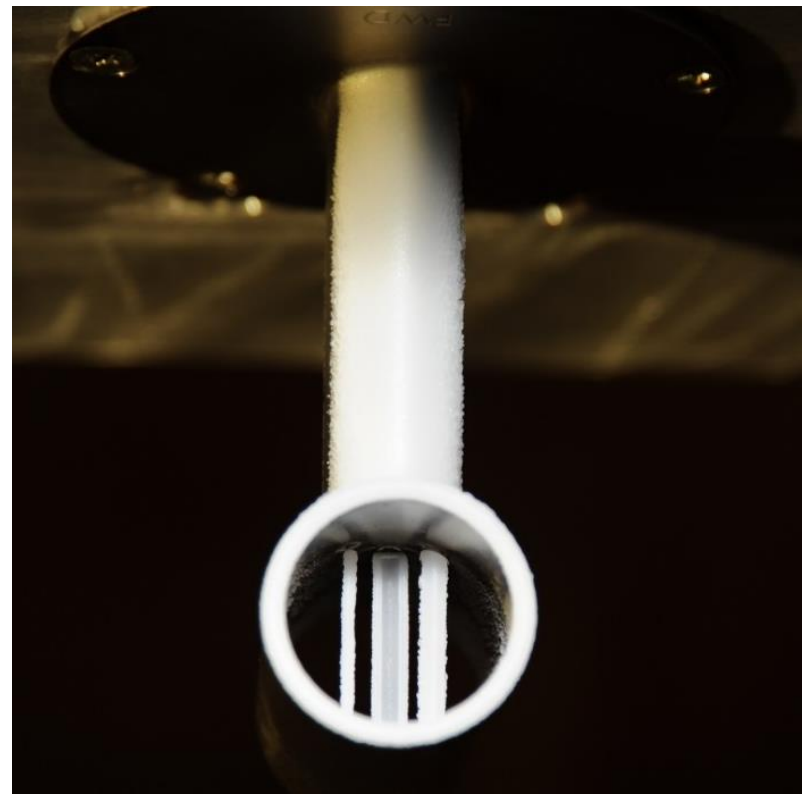

b) Multi-wire mounted under splitter plate

Figure 3. Photos from IRT tests to determine the effect of the mounting strut on the multi-wire sensor. Qualitative tests found that the sensors were "shadowed" near the support strut when the multi-wire was not mounted under a splitter plate. Figure (a) was tested at a total temperature of $-10^{\circ} \mathrm{C}$ and Figure (b) was tested at a total temperature of $-17^{\circ} \mathrm{C}$.

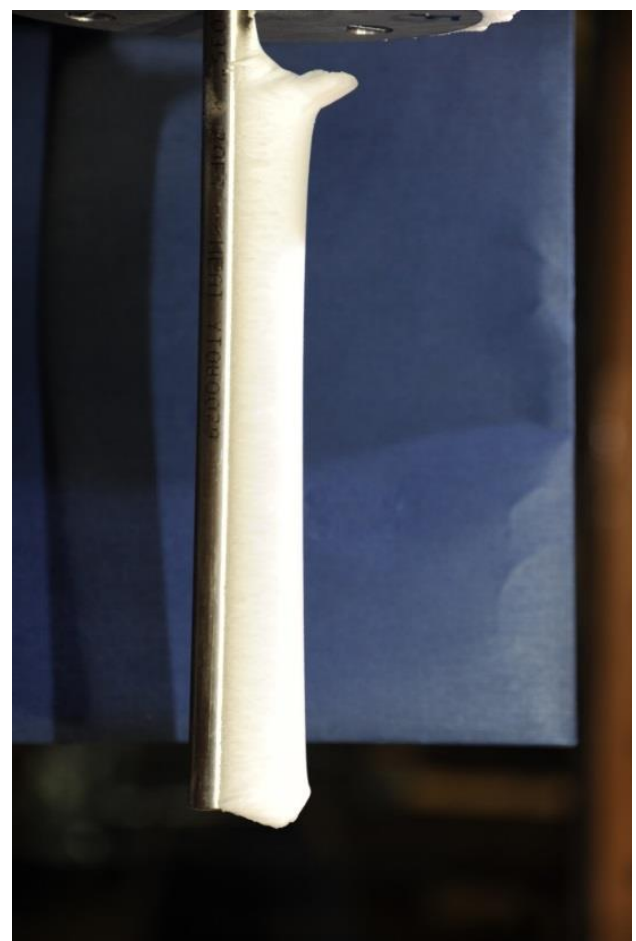

a) Iced rod on mounting strut, no splitter (7.2 min)

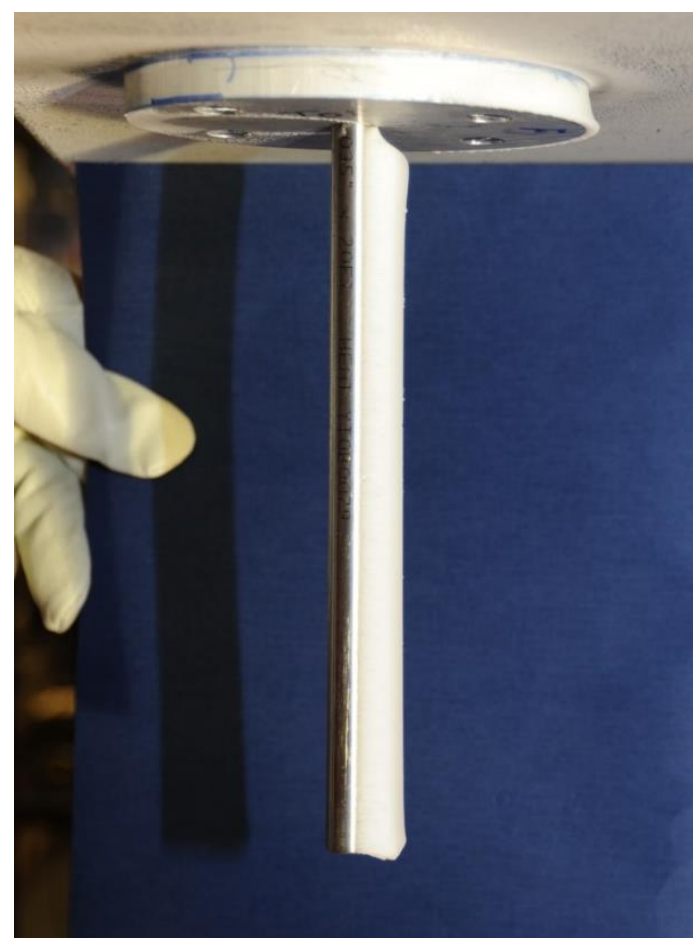

b) Iced rod under splitter plate (3.9 min)

Figure 4. Pictures from Rod tests, showing ice accretion with and without splitter plate. Conditions were 150 knots, MVD=15 $\mu \mathrm{m}, \mathrm{LWC}=0.5 \mathrm{~g} / \mathrm{m3}$. Spray times were not equivalent. 
multi-wire. Although the spray times were different, visual examination showed that the ice uniformity was better with the splitter plate, as seen in Fig. 4. These tests have demonstrated the importance of knowing the flow angularity into the multi-wire shroud. (Figure 5 shows the multi-wire mounted underneath the splitter plate.)

During testing, any ice that builds up on the leading edge of the splitter plate is removed between test points. It has been found (particularly for very high-impingement rate sprays) that a buildup of ice on the leading edge of the splitter plate can cause the multielement sensor to read LWC values higher than normal. Such conditions are easy to recognize in the data because the LWC continues to increase over the duration of the spray until the ice sheds, whereupon the LWC values drop back to where they were at the start of the spray. Such data have not been included in this report; it may also be noted this effect is typically seen at impingement rates above those included here, and/or at lower test section temperatures.

Furthermore, tests were conducted in 2009 and 2010 comparing multi-wire measurements with and without a splitter

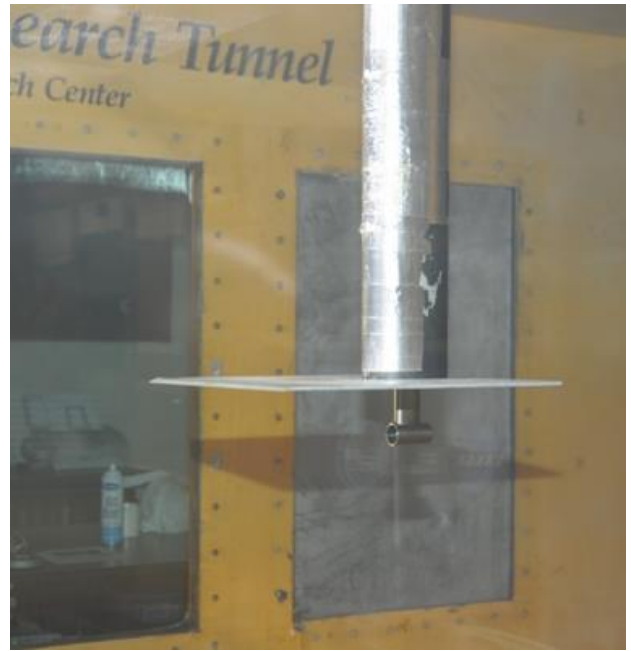

Figure 5. Multi-Element sensor mounted underneath a splitter plate. plate to the blade. After the multi-wire data were retroactively corrected for collision efficiency (see later section), which increased the multi-wire LWC values, the overall benefit of the splitter plate was found to be inconclusive for these data sets. However, as stated above, there is reason to believe the flow quality is improved by adding a splitter plate.

The IRT will continue to investigate options for an anti-iced mounting setup for the multi-wire that provides the greatest accuracy of measurement at all impingement rate values.

\section{Multi-Element Sensor Test Procedures}

For the majority of data acquisition with the multi-element sensor, the tunnel total temperature is held steady at $10{ }^{\circ} \mathrm{C}$, and tunnel airspeed is varied between 50-350 knots. Once the desired spray bar air pressure and water pressure are set and the data system has been properly tared, the cloud is typically sprayed for two minutes. After the spray is complete, tunnel conditions are held steady for the next 30 seconds so the researchers can make sure the pre- and postspray baselines for the multi-wire have remained the same. A shifted baseline could indicate a bad data point. Also, to check sensor repeatability, there are a few conditions that are measured multiple times over the course of the day, including at both the start and end of the test period. Results of these repeatability tests are given in the Test Results section.

Starting in 2013, the IRT staff began conducting health-monitoring checks on the multi-element sensor at the start of every test entry. These health-monitoring checks were started to check the stability of the hot wire system and ensure no drift over time. During these checks, the tunnel airspeed was held at 75, 150, and 250 knots, all at a total temperature of $+10^{\circ} \mathrm{C}$. These were "dry" tests, with no cloud issued from the spray bars. Spray bar air pressure was held at idle (1 psig). It was determined that the accuracy of the temperature setpoint was not important enough to use a substantial amount of test time to achieve it, and so the tunnel operators were told to set the tunnel total temperature within $0.5^{\circ} \mathrm{C}$ of $+10^{\circ} \mathrm{C}$, and focus more on ensuring the set airspeed and temperature were steady (with temporal variations less than 1 knot and less than $0.1^{\circ} \mathrm{C}$ ). The conditions were held steady for 2 minutes while the researchers recorded the tunnel conditions and power levels of all 4 sensing elements. Results from these health-monitoring tests are given in the Test Results section.

\section{E. Data Processing for the Multi-Element Sensor}

\section{Data Acquisition}

The IRT uses SEA's M300 Data Acquisition System along with their WCM-2000 system to collect data from the multi-element sensor. The M300 records the power output of each of the sensing elements and receives the facility conditions from the facility control system, including total temperature, static temperature, airspeed, static air pressure, spraybar nozzle pressures, and whether the spray is on or off. All necessary calibration values and sensing element dimensions are received from the probe, and these are used along with the received facility conditions such that the data system can correlate the power of each sensing element to a calculated LWC. All the recorded values are output as one-second averages into a CSV file. 

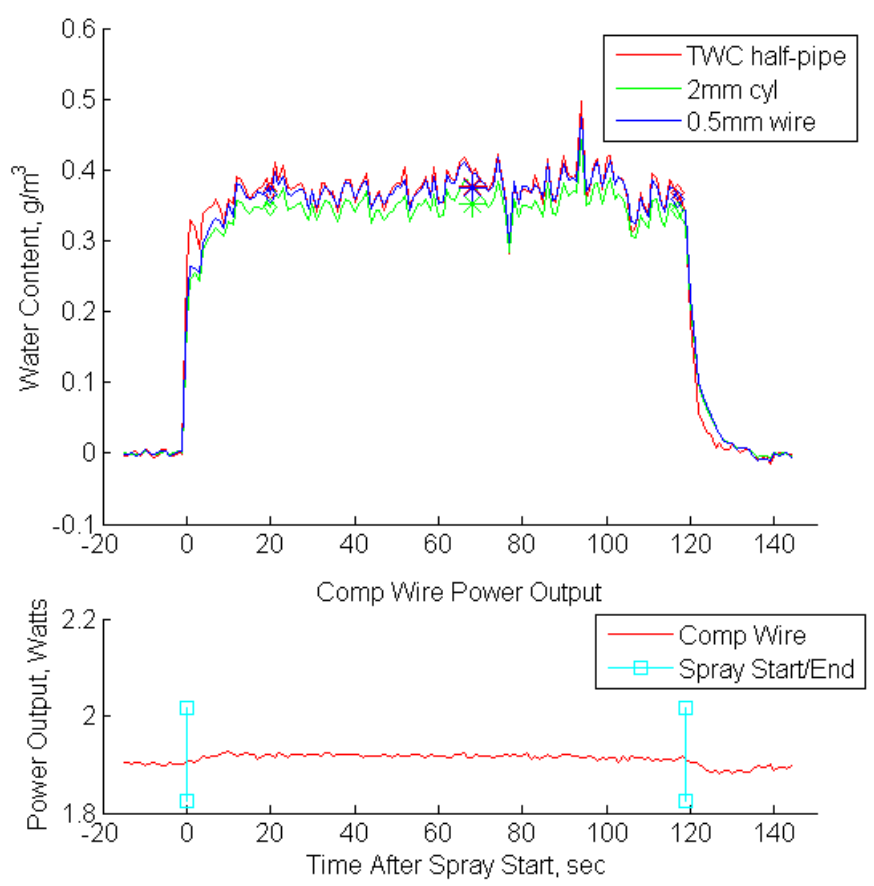

Figure 6. Example outputted plot from the in-house MATLAB code used to process multi-element sensor data. The top plot shows water content readings from the three vertical sensing elements, with asterisk markers showing the calculated average of the time-averaging segment, as well as diamond markers indicating the start and end of the time-averaged segment. The lower plot shows the corresponding comp wire trace. with markers for the start and end of the snrav time.

\section{Data Post-processing: MATLAB code}

Once the data has been retrieved from the $\mathrm{M} 300$, it is post-processed using a MATLAB ${ }^{\circledR}$ code that was developed inhouse. This code averages the data system outputs for each spray, starting 20 seconds after the spray begins and ending 2 seconds before the spray ends. The code calculates the pre-spray LWC values as a 10 -second average, starting 15 seconds before the spray start. These values are expected to be near zero, since the LWC readings from each sensor are typically tared before each spray begins. Even so, the pre-spray LWC values are subtracted from averaged during-spray LWC values, in order to ensure elimination of background effects. The post-spray LWC values are also calculated to determine if the background "dry" conditions changed substantially over the duration of the spray. The user is notified if the calculated LWC differ by more than $0.1 \mathrm{~g} / \mathrm{m}^{3}$ between the start and the end of the spray. Additionally, the power of the compensation wire is monitored, and the user is notified if the power drifts more than $\pm 5 \%$ from its value shortly after the spray begins, or if the comp wire power changes by more than $4 \%$ when the spray begins. A plot is generated for each spray, (example shown in Fig. 6), so that the user may view the profile of the data, compare it with the calculated values, and decide if the data seems reasonable. Substantial drifts in the LWC or compensation wire power over the course of the spray may indicate, for example, substantial ice buildup on the splitter plate leading edge. Such drifting may require the data to be disregarded, or further processed manually.

\section{Collision Efficiency Correction}

The smallest drops in the cloud are diverted around the sensing elements rather than impinging, particularly at low speeds, and so the measured LWC must also be corrected for the collision efficiency of the sensor (also frequently called the collection efficiency). The primary sensor element used for liquid water content measurements in the IRT is the $2.1 \mathrm{~mm}$ diameter forward facing half-pipe. In 2014, Rigby, Struk, and Bidwell modeled this sensing element along with the other two inside the multi-element sensor shroud using LEWICE3D, a particle trajectory code coupled with a three-dimensional flow field analysis. They determined the correlation between the drop collision efficiency and the modified inertia parameter for drop diameters of 5, 20, 50, and $100 \mu \mathrm{m}^{4}$. Struk then used this correlation to find total collision efficiency values based on particle size distributions measured in the IRT, rather than monodisperse drops $^{5}$. These values were in turn used to develop a formula for the collision efficiency correction as a function of MVD and airspeed in the IRT. Using this equation, collision efficiency corrections are applied to all data from the multi-element sensor to determine the actual cloud LWC based on the measured values. It may be noted that in 2012 the IRT staff started using a collision efficiency correction that was based on a 2D geometry of the sensing elements (an infinite half-pipe with no shroud). However, all the data in this report (taken before and after 2014) have been corrected with the collision efficiency correction based on the 3D geometry and the particle size distribution that was just described. This correction is only 1-2\% for drop sizes larger than $100 \mu \mathrm{m}$ at airspeeds above 100 knots, but the correction increases as drop-size and airspeed decrease. The water content may be as much as $10 \%$ higher than measured for a drop size distribution with an MVD of $20 \mu \mathrm{m}$ at 100 knots. For a drop size distribution with an MVD of $15 \mu \mathrm{m}$ at 50 knots, the correction is greater than $15 \%$.

American Institute of Aeronautics and Astronautics 

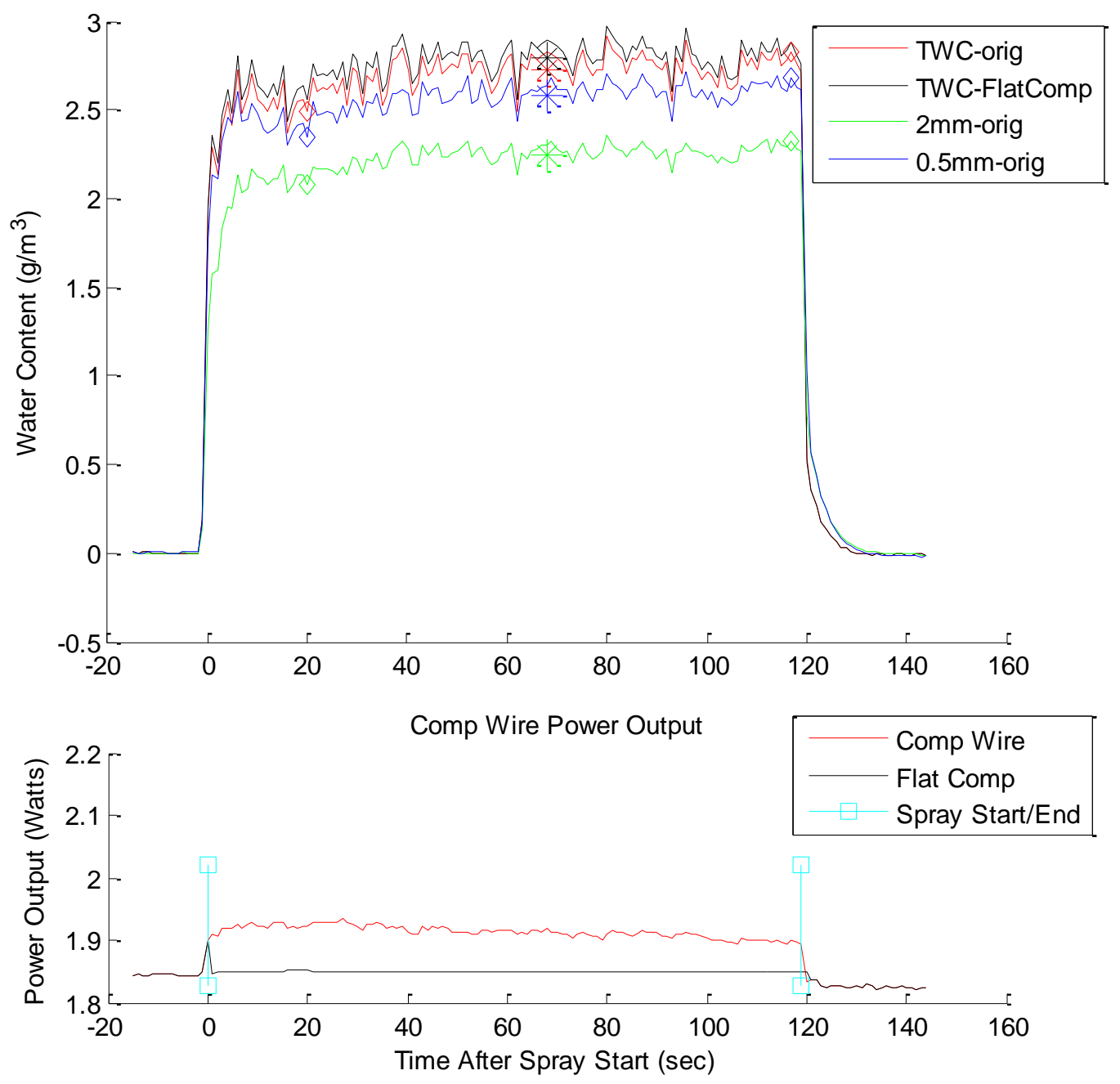

Figure 7. Example outputted plot from the in-house MATLAB code used to process multi-element sensor data. The top plot shows water content readings from the three vertical sensing elements, with diamond markers showing the start and end of the time-averaging segment, and large asterisk markers indicating the average water content for each element. Data is also shown calculating what the TWC would read if the comp wire was forced to a "flat" value, equaling the average of its pre-spray power. The lower plot shows the corresponding comp wire traces, real-time and forced flat, with markers for the start and end of the spray time.

\section{Applying Corrections for Comp Wire Jump}

For some conditions in the IRT, the comp wire power has exhibited a step-increase in power ("jump") at the same time that the spray begins. One example of this is shown in the lower, red trace of Fig. 7. Note that this figure shows traces for both the real-time measured comp-wire power, as well as the corrected "flat-lined" comp wire power and the corresponding TWC trace, which will be explained later in this section. Examining the multi-wire data from the January 2012 Full Calibration showed that the comp wire power may increase by as much as $8 \%$ of the pre-spray comp wire power. The cause for the increase in comp wire power has not been determined. The comp wire is supposed to record changes in ambient (dry) conditions, which include air temperature, airspeed, air pressure, and humidity. In a testing environment such as the IRT, these conditions are controlled to be constant. It is understood that when a spray begins, the air temperature could rise slightly due to the added heat of the water in the cloud, but this would cause the comp wire power to decrease, not increase. In some cases, the air humidity may also increase when the spray turns on, unless the airspeed is high enough that the static temperature is below the dew point, which creates a

American Institute of Aeronautics and Astronautics 


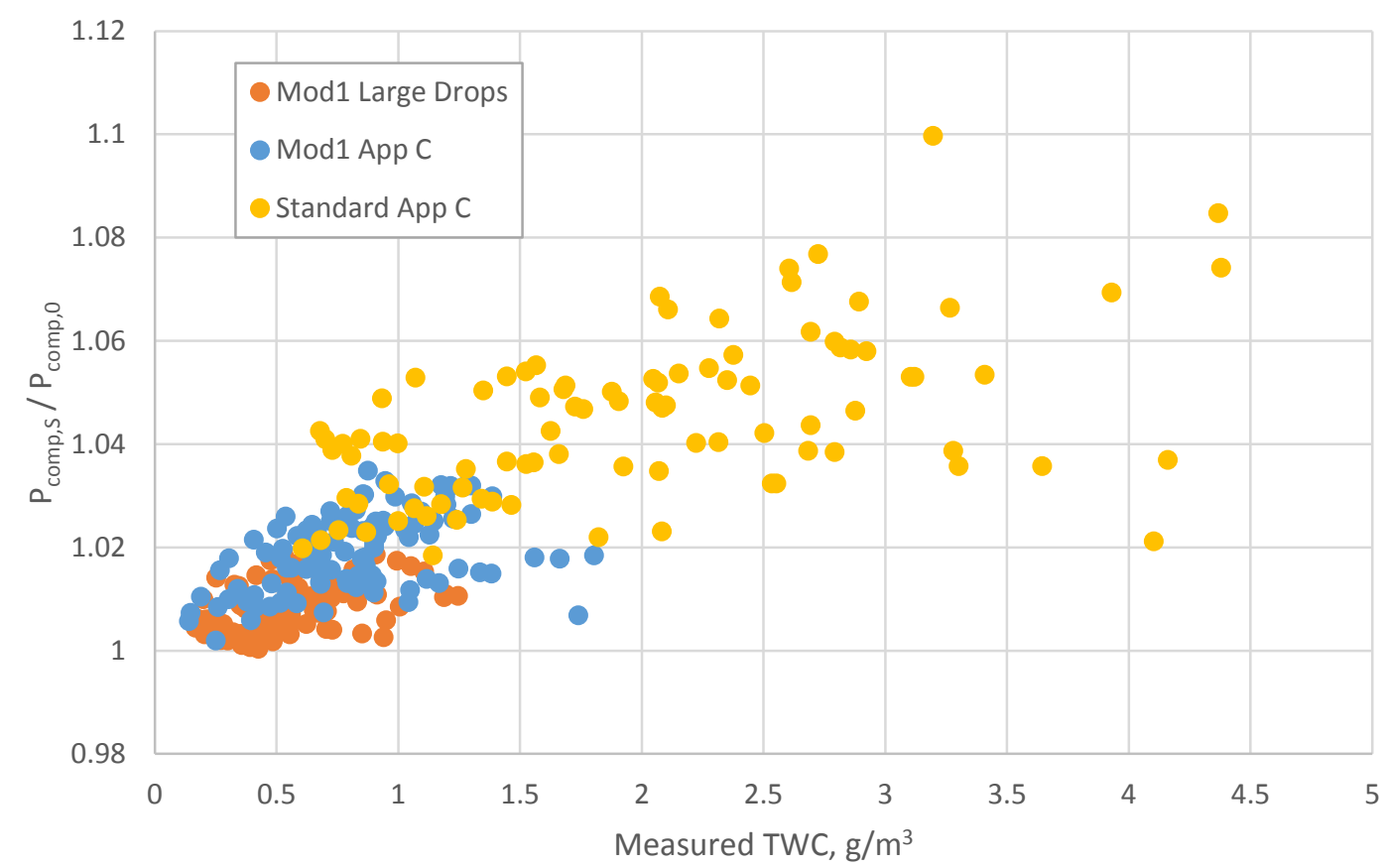

a) Change in compensation wire power vs. measured TWC

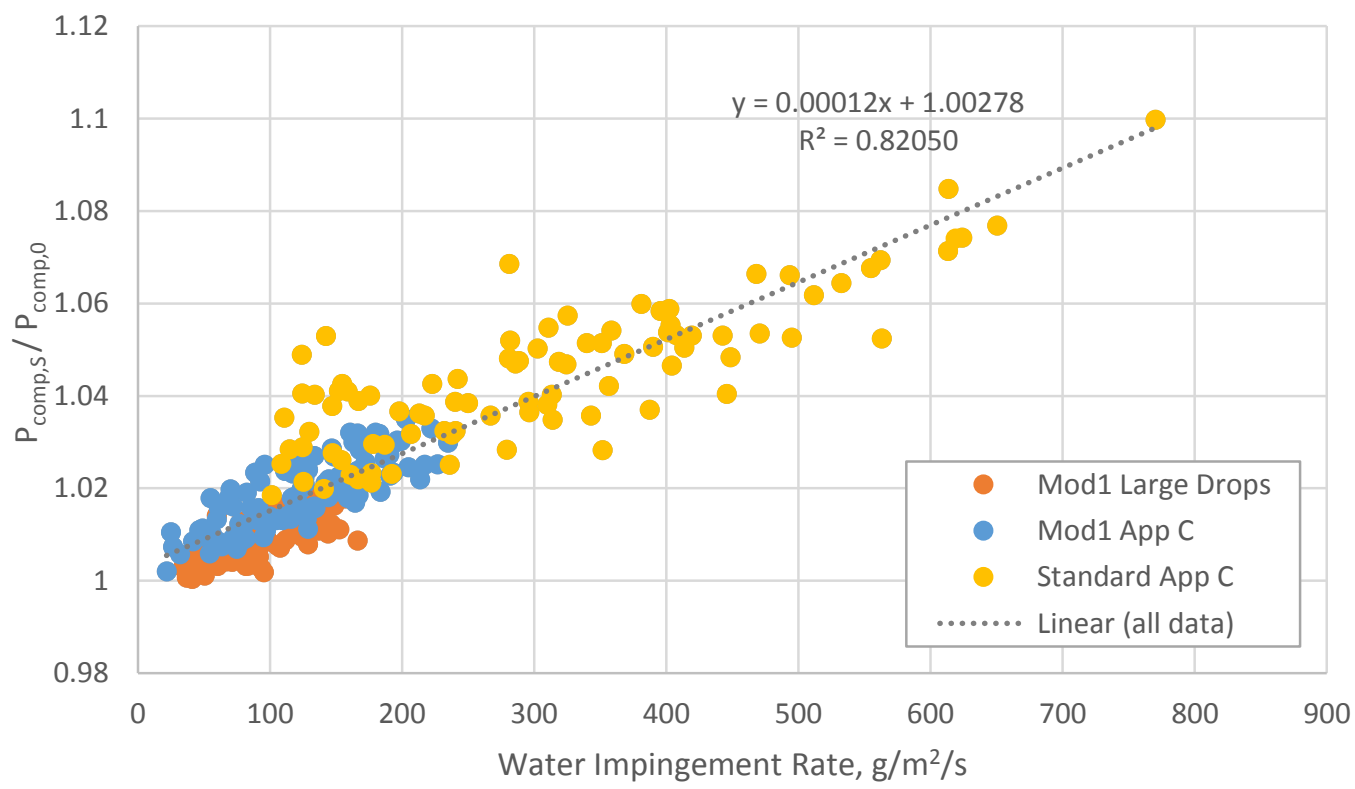

b) Change in compensation wire power vs. water impingement rate

Figure 8. Comparisons of the change in comp wire power at the start of the spray to the measured water content and water impingement rate. $P_{\text {comp, },}$ is the average of 20 seconds of comp wire power data, starting 20 seconds after the spray begins. $P_{\text {comp, },}$ is the average of 10 seconds of comp wire power data starting 15 seconds before the spray begins. The measured TWC is calculated as for all sprays: averaging the data starting 20 seconds after the spray begins and continuing until 2 seconds before the spray ends. The impingement rate is the measured TWC multiplied by the airspeed and the collision efficiency correction.

American Institute of Aeronautics and Astronautics 


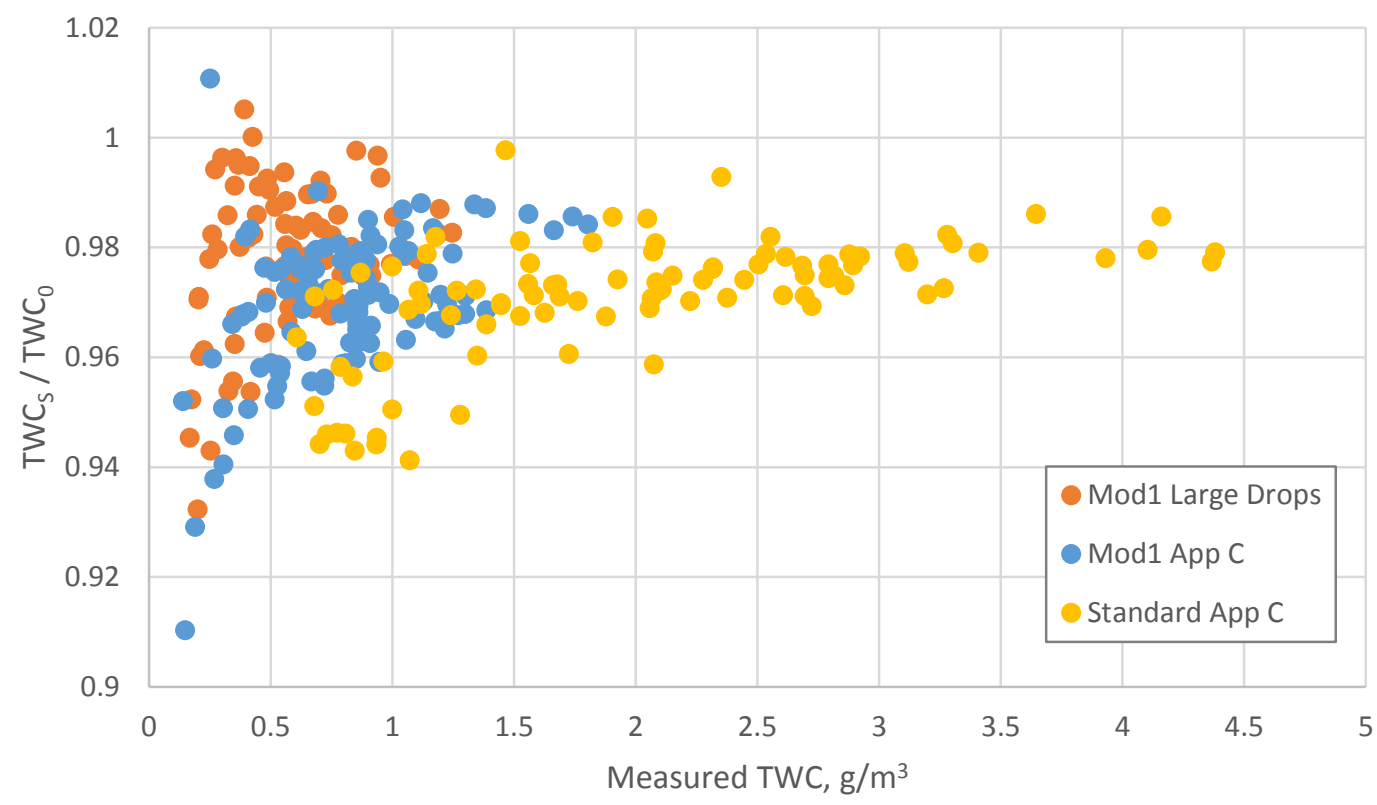

a) Change in measured TWC vs. original measured TWC

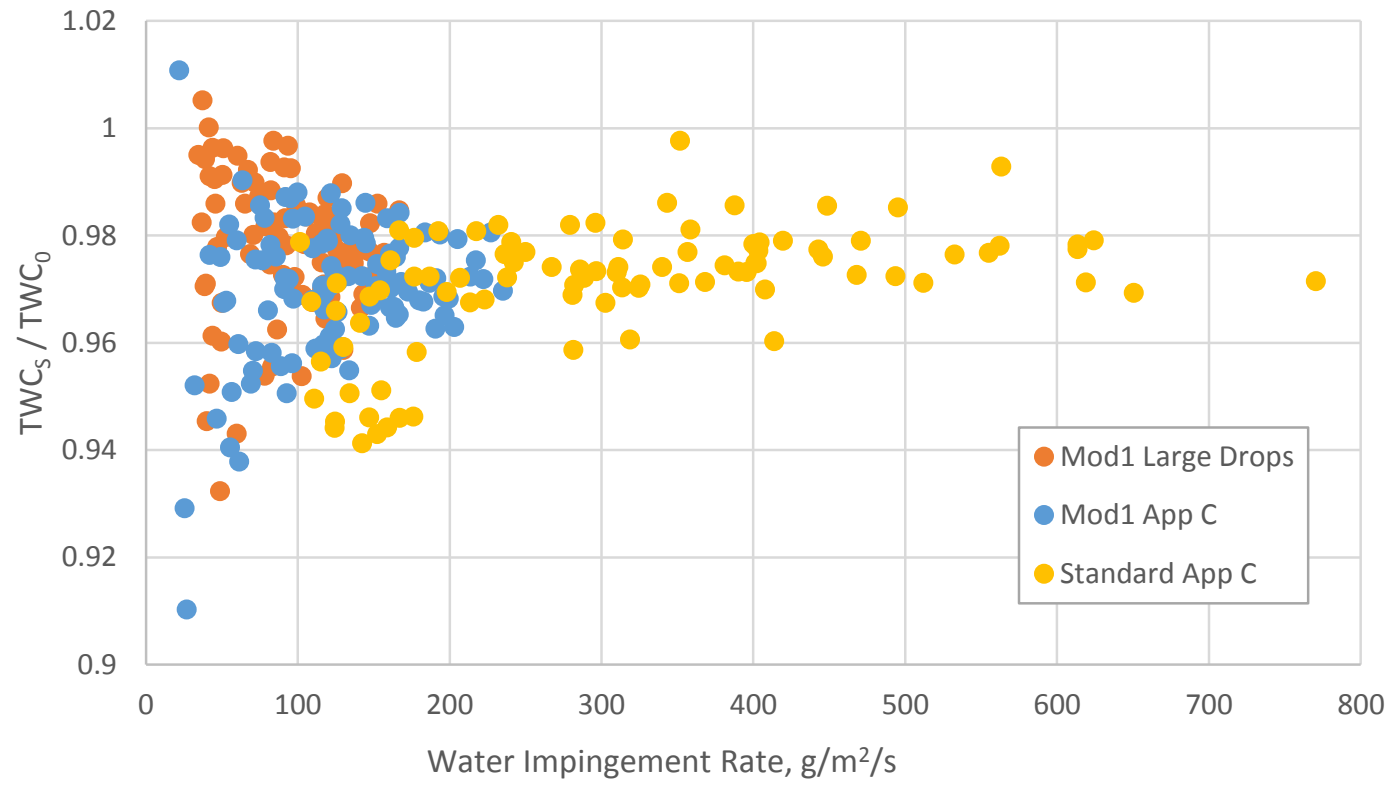

b) Change in measured TWC vs. Water Impingement rate (calculated from original measured TWC)

Figure 9. Comparisons of the change to the measured TWC vs. the uncorrected, measured TWC and vs. the impingement rate. TWCs is the total water content calculated using the real-time (during-spray) comp wire power. $\mathrm{TWC}_{0}$ is the total water content calculated from the flat-lined comp wire power that is the average of 20 seconds of data taken before the spray began. The impingement rate is the uncorrected, measured TWC multiplied by the airspeed and the collision efficiency correction. The graph shows that at higher water contents, the originally-measured $\mathrm{TWC}_{\mathrm{S}}$ is about $2 \%$ lower than the corrected $\mathrm{TWC}_{0}$.

American Institute of Aeronautics and Astronautics 
condensation cloud. Since the comp wire jump is also seen at these higher speeds, it seems unlikely that the increasing humidity is causing the increase in comp wire power.

Further examination of the data showed a correlation between the power increase exhibited by the comp wire and the measured water content of the spray condition, as shown in Fig. 8a. This data may be further analyzed by calculating the impingement rate, which is:

$$
\text { Impingement Rate }=L W C * \text { Airspeed } * E_{H P}
$$

Where $E$ is the collision efficiency of the half-pipe element. By using this equation and applying it to the data in Fig. $8 \mathrm{a}$, a better correlation is observed between the comp wire power increase and the water impingement rate, which is shown in Fig. 8b. This correlation could suggest that the power increase is due to some sort of wetting of the comp wire from the spray. This theory may be reinforced by noting that the comp wire power usually shows a step-increase and step-decrease in power at the same time the spray begins and ends, respectively. The data in Fig. 8 were taken with the SN 2023 sensing element, which has the $0.5-\mathrm{mm}$ wire in the center in front of the comp wire. Similar data analysis with other sensor configurations gave similar results, and there could be no conclusions drawn about what element configuration was "best" in terms of shielding the comp wire. The IRT staff concluded from this that the comp wire power should not be increasing when the spray begins, and took steps to correct the data accordingly and understand the effect on the measured TWC.

In 2016, with the help of SEA, the data acquisition code in the M300 was modified slightly to record two values for the comp wire power: one based on real-time measurements, and one that was "flat-lined" to equal the pre-spray comp wire power for the duration of the spray. Correspondingly, two LWC values were calculated and recorded for each of the three vertical elements: one based on the real-time comp-wire power and one based on the flat comp wire power. Figure 7 includes the "flat-lined" comp wire power, which is set to be the average of the 20 seconds taken before the spray began. This trace shows a small spike in comp wire power at the start of the spray because the combined time that it takes the control system to communicate to the data system that the spray has turned on is about 1-2 seconds. Figure 7 also contains the water content from the TWC element that is calculated based on this flat-lined comp wire power. Figures $9 \mathrm{a}$ and $9 \mathrm{~b}$ were created by applying this correction to the January 2012 Full Calibration data and comparing the results. Note that the data shows a convergence towards $2 \%$ at higher liquid water contents, even though Fig. $8 \mathrm{~b}$ suggested that the comp wire power continually increases as the impingement rate increases. To understand this, refer back to Eq. (1) and Eq. (2); when there is more water in the cloud, the wet-power of the other sensing elements is higher, such that changes in the comp wire do not have the same relative impact on calculated LWC. Meanwhile, the reverse is also true, such that at low water contents, small changes in comp wire power can have large impact on calculated LWC. Note that at these low water contents, even though the percentage change in LWC is large, the overall difference in LWC may still be only a few hundredths of a $\mathrm{g} / \mathrm{m}^{3}$. It may be noted that other sensor head configurations were also studied in this same way, and the results were found to be comparable.

It is for this reason that the code was modified to calculate LWC based on both the real-time comp wire power and the flat, pre-spray comp wire power. The multi-wire data that is included in this report has been corrected by using the flat-lined comp wire power, except where indicated otherwise.

Note that this is not the only time the comp wire has been observed to read higher dry power levels in a cloud, as was noted by Strapp \& Lilie ${ }^{6}$. They used a Nusselt Number-Reynolds Number (Nu-Re) regression to predict the dry air power when the spray is off, and used the predicted value as the dry power term to calculate TWC. They found that doing so increased the LWC by an average of $4 \%$, which is comparable to results presented here.

\section{F. Discussion of Multi-Wire Capabilities \& Limitations}

Early on in testing, the multi-wire was found to have greater capabilities than the Icing Blade in that it has less limitations on operations. It can be run at any air temperature, for any length of spray duration, and at a much wider range of cloud liquid water content and drop diameter conditions. The sensor also has much greater test efficiency, allowing the user to collect many more data points over the span of a test day. Additionally, the different element designs also enable the user to detect the presence of ice crystals in the cloud, because the 2-mm and $0.5-\mathrm{mm}$ cylindrical elements are designed to only measure liquid water, while the $2-\mathrm{mm}$ forward-facing half pipe is designed to capture and measure both liquid water and ice water.

However, while the multi-wire has been found to be a significant improvement over the Icing Blade, it is also important to recognize the sensor's limitations. Data from testing in other facilities suggests that at high liquid water contents, the multi-wire may suffer from minor effects of incomplete evaporation (pooling), and perhaps also suffer from splashing when there are ice crystals or large drops present $t^{4,7}$. It should also be noted that in some environments, the multi-wire elements can become coated due to minerals in the cloud liquid water that remain after evaporation.

American Institute of Aeronautics and Astronautics 
This problem has been seen in NASA Glenn's Propulsion Systems Laboratory, where city water may be sprayed through the nozzles in order to create ice crystals. In such environments, the elements will need to be regularly cleaned to remove the mineral deposits. Since the IRT water is filtered and deionized, this problem has not been seen in the IRT. The sensing elements have been cleaned with no apparent effect on measurement, and health-monitoring tests have shown no change in dry power readings, as discussed later in this report.

\section{The Icing Blade}

In contemplating using the multi-element sensor as the primary calibration tool for the IRT cloud liquid water content, it must first be validated against a more well-understood instrument. The icing blade has been the standard measurement tool for all liquid water content calibrations in Appendix C icing conditions in the IRT since 1980.

\section{A. Instrument Description \& Test Procedures}

The Icing Blade (or simply "the blade") is $3.18 \mathrm{~mm}$ wide by $154 \mathrm{~mm}$ long by $19.05 \mathrm{~mm}$ thick. It is mounted in such a way that it is located at the horizontal centerline and the vertical center of the test section (Fig. 10). It is run at a tunnel total air temperature between -18 and -20 ${ }^{\circ} \mathrm{C}$ in an attempt to ensure that rime ice is accreted on the $3.18 \mathrm{~mm}$ flat face in most cases.

For any given spray condition the tunnel is brought to the desired airspeed and the tunnel spray system is turned on for a prescribed time that will result in an average ice thickness of $3.8 \mathrm{~mm}$ on the blade. The tunnel airspeed is brought to zero and the iced blade thickness is measured with chilled digital calipers in three vertical locations: centerline and centerline $+/-25.4 \mathrm{~mm}$. The ice width is also measured to ensure it does not exceed $5 \mathrm{~mm}$. The median of the 3 measurements is used for the calculation of LWC using Eq. (3).

$$
L W C=\frac{1710 \cdot d}{V \cdot t \cdot E_{b}}
$$

Where: 1710 is a constant containing unit conversions and an assumed ice density of $0.88, d$ is the ice thickness in millimeters, $V$ is the tunnel airspeed in knots, $\mathrm{t}$ is the spray time in seconds, and $E_{b}$ is the blade collision efficiency. The collision efficiency $E_{b}$ is calculated as a function of airspeed, air density and drop size using the FWG two-dimensional particle trajectory code ${ }^{8}$.

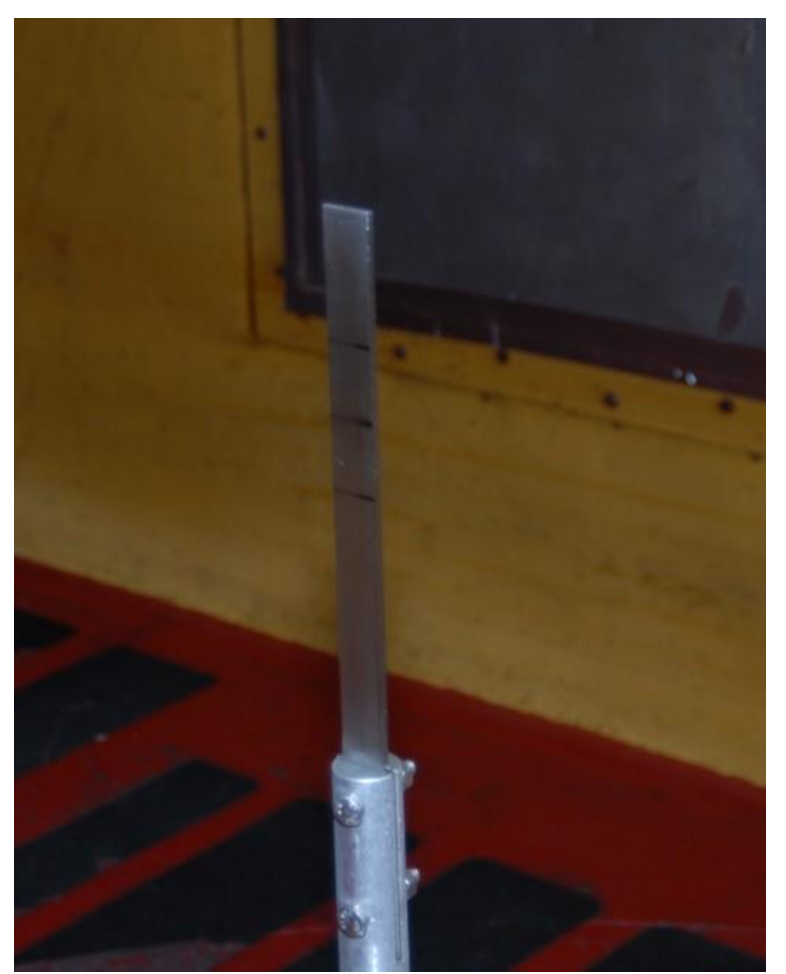

Figure 10. The icing blade, mounted in the center of the IRT test section. Dimensions are $3.18 \mathrm{~mm}$ wide by $154 \mathrm{~mm}$ long by $19.05 \mathrm{~mm}$ thick (0.125 in. by 6 in. by 0.75 in.)

\section{B. Discussion of Icing Blade Capabilities \& Limitations}

The greatest advantages to using the blade are its simplicity and its reliability. There is no data communication system to be concerned about. Mineral build-up is less of a concern with the blade because the ice is scraped off after every spray (not evaporated). Additionally, the researcher may observe the characteristics of the ice that is accreted on its surface and thus have a better understanding of the cloud conditions. If the ice is "pointed," akin to an arrowhead shape, it indicates there are ice crystals present in the cloud that are ablating the surface. If the width of the ice is too great, particularly if the ice has ragged edges, it indicates the water content may be so high that not all the impinging liquid water is freezing onto the forward-facing surface. The blade has also proven to be a reliable instrument for low impingement rates. Over multiple decades of calibrations and check-calibrations in the IRT, the blade LWC measurements have overall been repeatable to around $\pm 5 \%$, particularly for lower impingement rate values.

Stallabrass ${ }^{9}$ performed an assessment of the various sources of error for both the icing blade and a small rotating cylinder. The general conclusion was that the errors were "relatively small", on the order of $5 \%$ or less. He also found that the rotating cylinder and icing blade agreed to within $5 \%$ or less. He concluded that these were "simple and

American Institute of Aeronautics and Astronautics 
accurate methods of liquid water content measurement in applications where ready access to the droplet laden airstream is possible."

However, there are some substantial limitations to the use of the icing blade. The LWC range over which the blade can be used is limited by the Ludlam Limit ${ }^{10}$. The Ludlam Limit can be defined as the supercooled water impingement rate above which not all impinging water will freeze for a given air temperature. Water impingement rate is found by multiplying the airspeed, LWC and collision efficiency. Essentially, when the impingement rates are too high at a given air temperature, not all the impinging water accretes on the blade, and the calculated LWC is lower than what actually exists in the cloud. Stallabrass calculated the Ludlam limit for a $2.54 \mathrm{~mm}$ diameter rotating cylinder ${ }^{9}$, as shown in Fig. 11. In applying his calculations to the icing blade, two considerations need to be made. First, the collision efficiency may be different between the cylinder and the blade. The IRT has previously examined the difference in collision efficiency between a $3.18 \mathrm{~mm}$ blade and a $2.54 \mathrm{~mm}$ cylinder, during a series of tests run in 1998. Collision efficiency calculations were made for airspeeds of 150 and 224 knots and for MVDs between 16 and $270 \mu \mathrm{m}$ using the FWG two-dimensional particle trajectory code ${ }^{8}$. The collision efficiencies were found to be within $2 \%$ of each other for all conditions. Second, Stallabrass used the static temperature for his calculations, which is likely more

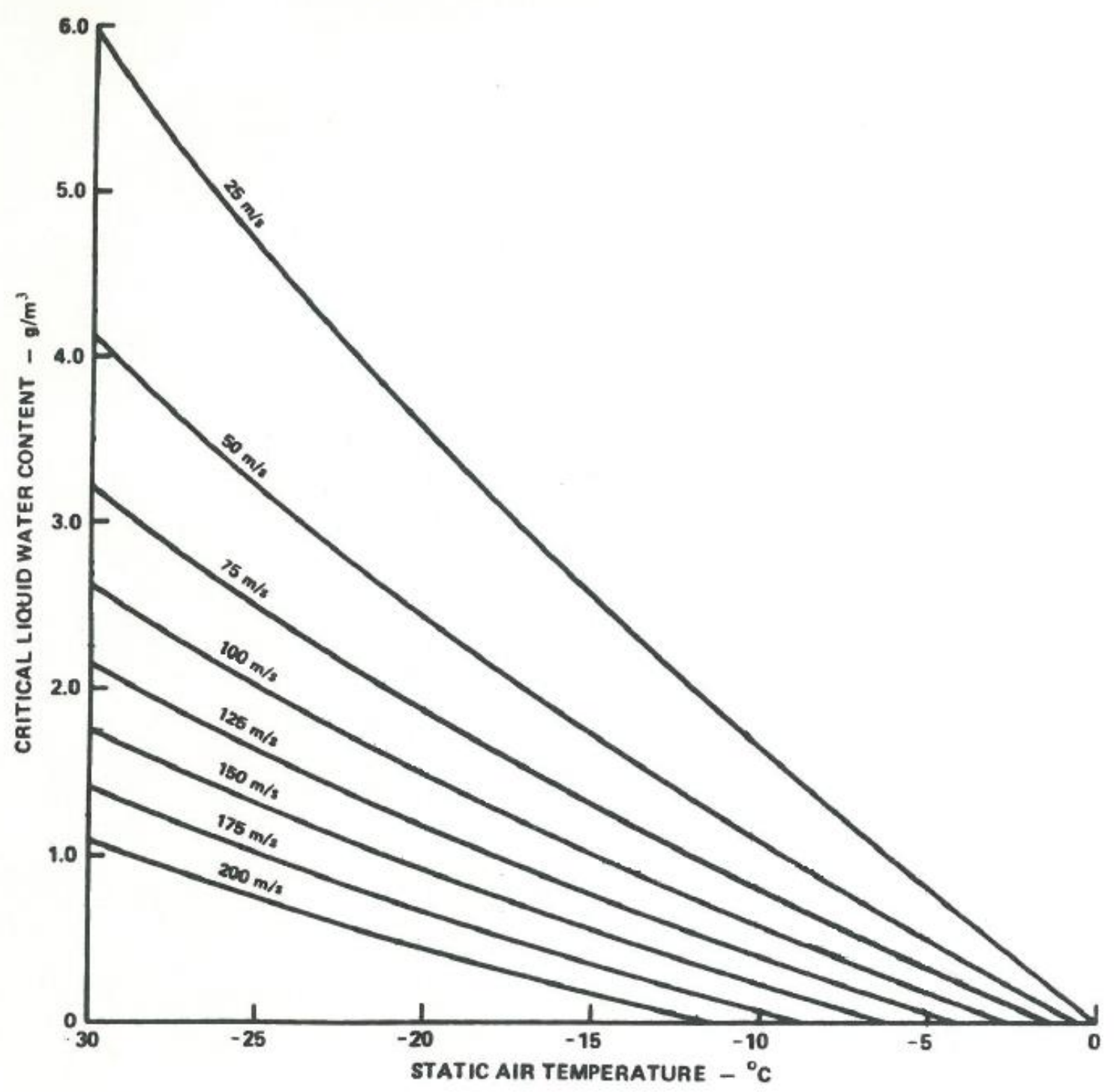

Figure 11. The Critical Liquid Water Content (Ludlam Limit) for a $2.489 \times 10^{-3} \mathrm{~m}$ Cylinder, as determined by Stallabrass'.

American Institute of Aeronautics and Astronautics 


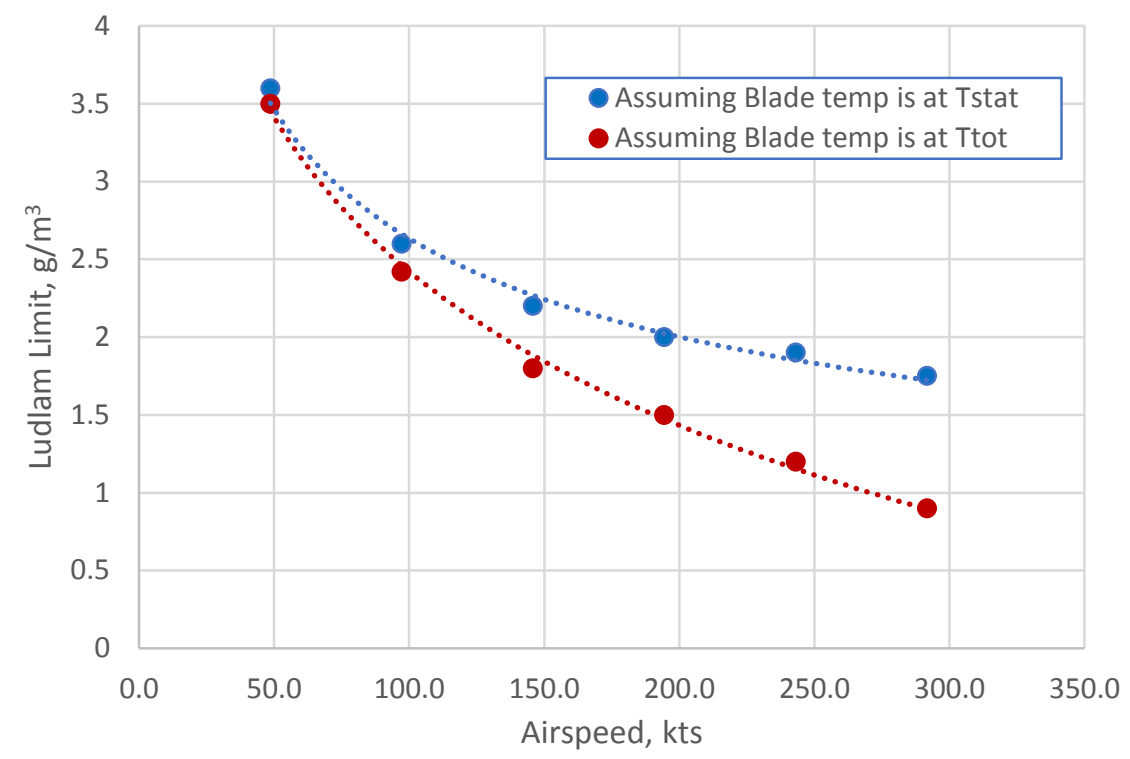

Figure 12. Stallabrass's Ludlam Limit calculations, applied to the $1 / 8^{\text {th }}$ inch blade tested at a total temperature of $-20^{\circ} \mathrm{C}$. One curve assumes the blade is at the total temperature (Ttot), and one curve assumes the blade is at the static temperature (Tstat). The actual temperature of the blade must be between these values. appropriate for a rotating cylinder. Figure 12 shows Stallabrass's calculations applied to the $3.18 \mathrm{~mm}$ blade, tested at a total temperature of $-20^{\circ} \mathrm{C}$. In this figure, there are two Ludlam Limit curves, one that assumes the blade is at the total temperature (Ttot), and one that assumes the blade is at the static temperature (Tstat). The temperature of the face of the blade must be between these two temperatures, so by plotting both lines, the bounds of the Ludlam Limit may be understood, even if the exact value is not. It can be seen that the LWC range over which the icing blade can be used decreases as the airspeed increases. Above the Ludlam Limit, the ice width on the icing blade

increases and some water is lost through runoff or blow off. This is why the width of the ice on the blade is measured and data is only accepted if the width is $5 \mathrm{~mm}$ or less. The Ludlam limit significantly impacts the range of conditions over which the icing blade can be used during tunnel calibrations and results in the LWC calibration being extrapolated for higher values.

The LWC error from the blade can also be amplified in high-LWC conditions because these tend to require shorter spray times. If the LWC is high enough that the spray is less than 20 seconds long (to avoid creating wide ice shapes), then even a 1 -second error in the understood spray time can cause a 5\% error in calculated LWC. In practice the icing blade was used for exposure times as short as 12 seconds.

The other limitation for use of the icing blade is the potential for mass loss due to splashing. That is, some of the water content does not freeze but rather splashes off the face and into the freestream, thereby reducing the amount of accreted ice. The potential for mass loss increases with increasing airspeed and drop size. Evidence of mass loss is demonstrated later in this report through comparisons with the SEA Multi-Element sensor.

\section{Test Conditions}

The majority of tests results discussed in this paper were part of cloud calibration efforts. For these tests, test section airspeed ranged between 50 and 350 knots. Liquid water content values ranged between 0.2 and $4.5 \mathrm{~g} / \mathrm{m}^{3}$, with the maximum and minimum LWC dependent on test section airspeed. Drop sizes ranged approximately between an MVD of $15 \mu \mathrm{m}$ and $230 \mu \mathrm{m}$. Tests with the blade were most commonly conducted at a total temperature between -18 and $-20{ }^{\circ} \mathrm{C}$. Tests with the multi-wire were most commonly conducted at a total temperature of $-10^{\circ} \mathrm{C}$.

\section{Test Results}

\section{A. Multi-Wire Dry Power Checks}

As described in the Multi-Wire Procedures section, the IRT staff has been doing "health-monitoring" of the multiwire by measuring the dry power levels of all the sensing elements at a total temperature of $+10{ }^{\circ} \mathrm{C} \pm 0.5^{\circ} \mathrm{C}$, and at airspeeds of 75,150 , and 250 knots. For these conditions, and in the interest of saving test time, it was more important that the temperature be steady than it be close to $+10^{\circ} \mathrm{C}$. Data were collected for the SN 2023 element over 7 test entries spanning more than 2 years. For this sensor head, at 75 knots the standard deviation is $2.0 \%$ of the average TWC power. At 150 knots, the standard deviation is $1.1 \%$ of the average power. At 250 knots, the standard deviation is $3.0 \%$ of the average power. Note that at 250 knots, there is often a condensation cloud in the IRT test section 
because the dew point is higher than the static temperature. For this airspeed, the element dry power appears to have some correlation to the moisture in the tunnel air. There was no definite correlation observed between relative humidity and element power reading at the slower airspeeds, where no condensation cloud is observed.

\section{B. Multi-Wire and IRT Repeatability}

To check the combined repeatability of the IRT and the multi-wire, two specific test conditions were repeated multiple times during each test entry, one using the Mod1 nozzles and one using the Standard nozzles, both at 150 knots, at a total temperature of $-10{ }^{\circ} \mathrm{C}$, and with an MVD of around $20 \mu \mathrm{m}$. All tests were completed with a single multi-wire head (SN 2023). Note that this analysis provides neither the repeatability of the multi-wire alone, nor of the IRT cloud alone, but of both together, for this condition. For this report, the results from five different test entries spanning two years were examined; there were a total of 27 measurements for the Mod1 nozzles and 29 measurements for the standard nozzles. The standard deviation of the Mod1-nozzle condition was $2.55 \%$ of the mean value, and the standard deviation of the Standard-nozzle condition was $2.25 \%$ of the mean value.

\section{Comparing the Multi-Wire to the Icing Blade}

The blade and the multi-wire were compared for Appendix C ("typical" icing) ${ }^{11}$ conditions as well as Appendix O (supercooled large drop) conditions ${ }^{12}$. The data from these tests were used to determine the capabilities and shortcomings of each instrument.

\section{Multi-wire compared to Icing Blade, with respect to Liquid Water Content}

Figure 13 shows measured LWC from the multi-wire compared to the blade for an airspeed of 150 knots and drop size of $20 \mu \mathrm{m}$, median volumetric diameter (MVD). This figure shows data from the IRT's two sets of spray nozzles: the Mod1 nozzles and Standard nozzles. Recall that these nozzles primarily differ in that the Standards have a higher water flow rate, and thus produce higher LWC. Figure 13 shows that the two instruments compare well at lower liquid

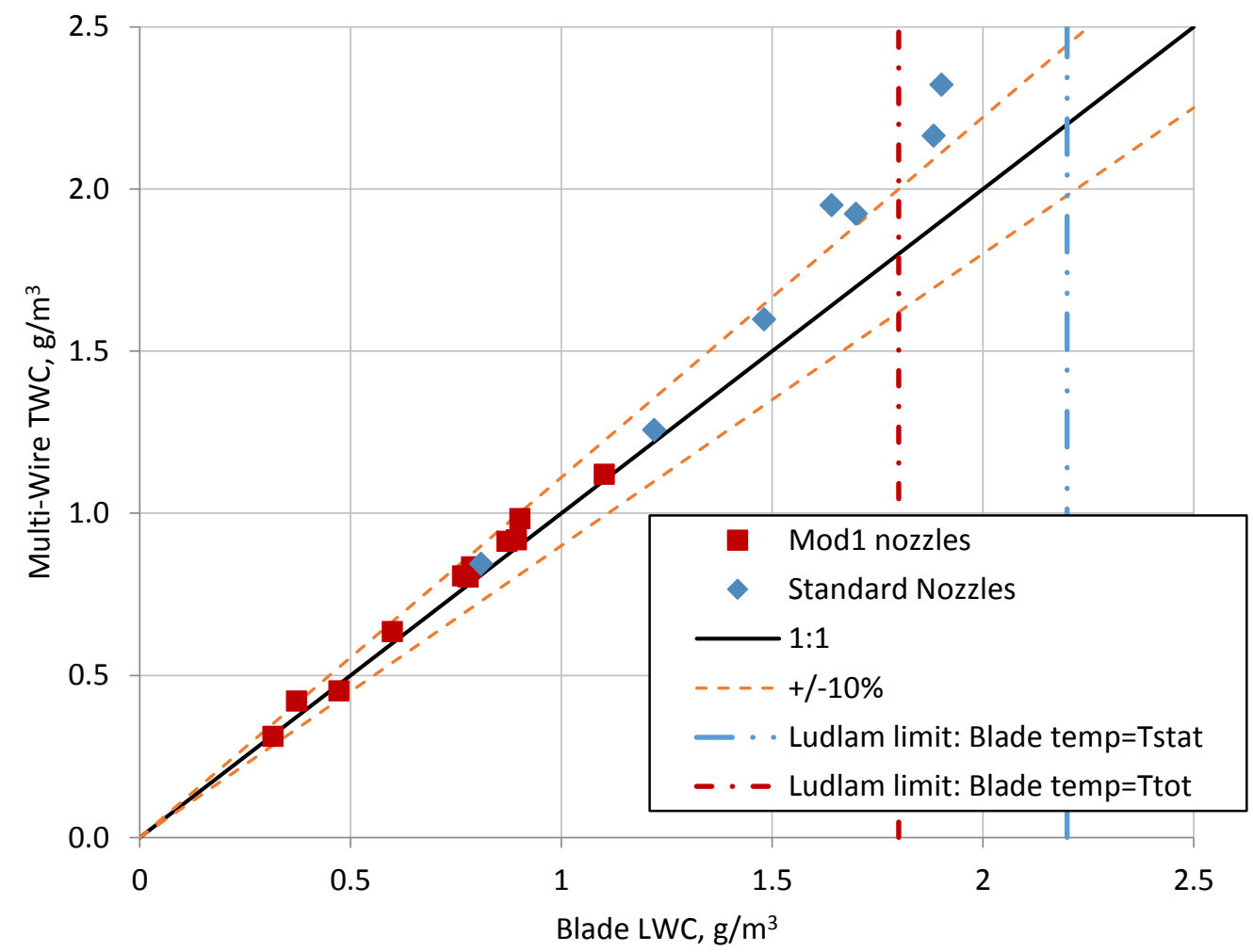

Figure 13. Measured LWC from the multi-wire compared to the blade for an airspeed of 150 knots and drop size of $20 \mu \mathrm{m}$, median volumetric diameter (MVD). As its Ludlam limit is approached, the blade tends to read lower than the multi-wire.

American Institute of Aeronautics and Astronautics 


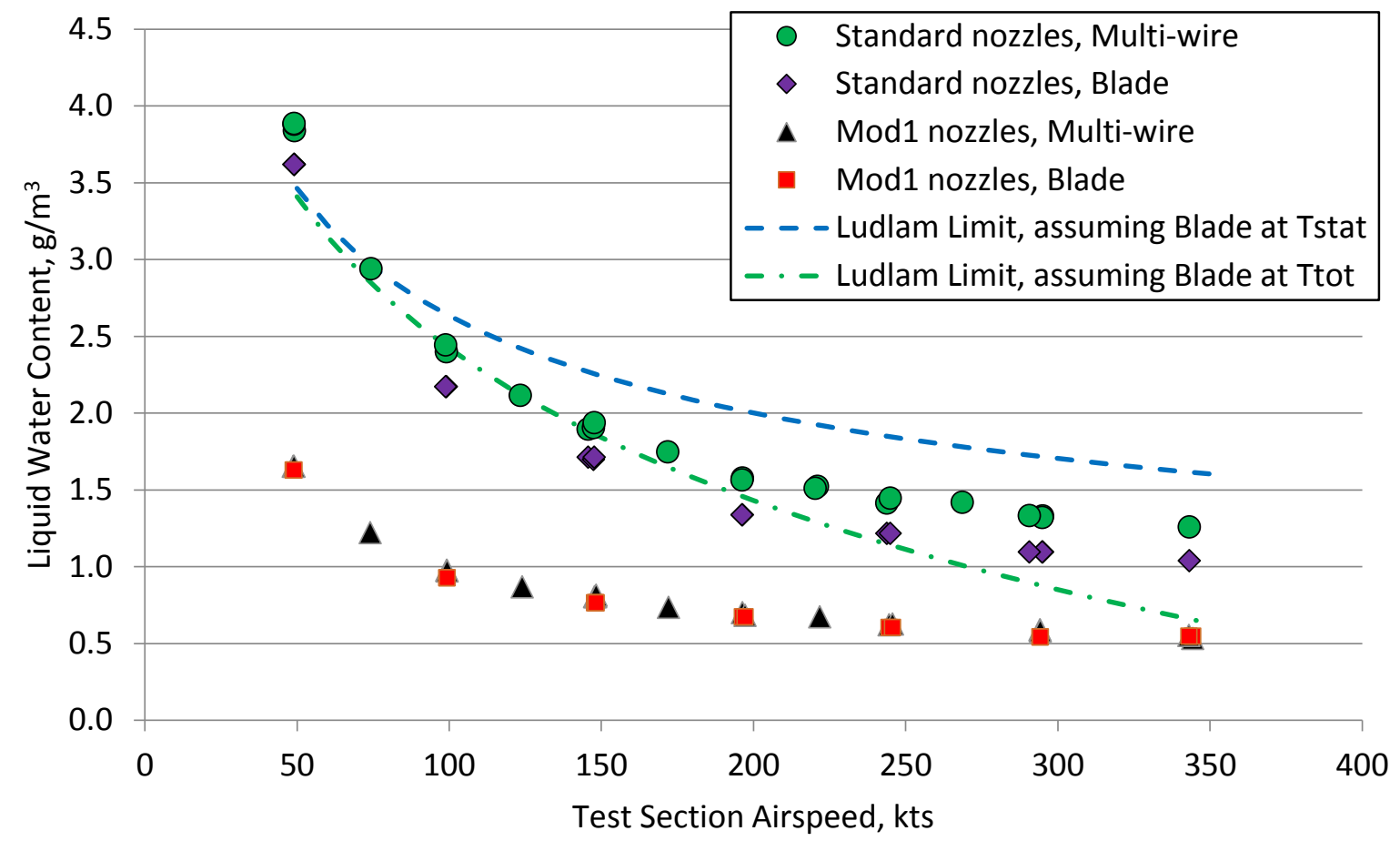

Figure 14. Comparing liquid water content measurements from the blade and the multi-wire, varying tunnel airspeed. Again, as its Ludlam limit is passed, the blade tends to read lower than the multi-wire.

water contents, but as the LWC increases above $1.8 \mathrm{~g} / \mathrm{m}^{3}$, which is the Ludlam Limit for the blade at the total temperature, the multi-wire measures noticeably (more than 10\%) higher than the blade.

2. Multi-wire compared to Icing Blade, with respect to tunnel airspeed

Similarly, Fig. 14 shows how the liquid water content measurements compare over a range of airspeeds. The two instruments compare well for the Mod1 nozzles, but the blade measures lower than the multi-wire for the standard nozzles. By comparing the Mod1 nozzle data with the standard nozzle data on this plot, it is evident that the difference between the two instruments is not due to water content alone or airspeed alone, but to both combined. This is consistent with the definition of Ludlam Limit, which is found from water impingement rate. Thus, there is reason to believe that at these higher impingement rates, not all the water that is impinging on the blade is accreting, and so measurements of the multi-wire are more accurate than the blade at higher impingement rates.

\section{Multi-wire compared to Icing Blade for large-drop conditions}

Further comparative tests were done between the blade and the multi-wire covering the full range of drop sizes in the IRT. Drop size is described using the median volumetric diameter (MVD). It was found from these tests that for a given spray bar air pressure, the more the drop size increased, the greater the separation between the blade and the multi-wire, as can be seen in Fig. 15, which plots the LWC measurements from each instrument for three different spray bar air pressures and three different airspeeds. What is difficult to discern in this figure, however, is whether the blade measures lower than the multi-wire because the drop size is increasing, or because the liquid water content is increasing. To further this analysis, the data in Fig. 15 is plotted in a new way in Fig. 16. Here, the LWC from each instrument are compared directly for the three different airspeeds. Different symbol colors indicate different ranges of drop size. The white symbols represent the smallest drops $(14 \mu \mathrm{m}<\mathrm{MVD}<50 \mu \mathrm{m})$, the blue symbols represent the middle-range drops $(50 \mu \mathrm{m}<\mathrm{MVD}<125 \mu \mathrm{m})$ and the red symbols represent the largest drops $(125 \mu \mathrm{m}$ $<$ MVD $<250 \mu \mathrm{m})$. The white symbols in Fig. 16 show that the blade and the multi-wire compare well for lower values of LWC, although the blade still measures lower at the highest water content values on each plot. Comparatively, the blue symbols show the blade measures lower than the multi-wire at even lower values of LWC, while the red symbols indicate that the blade measures lower than the multi-wire at all LWC values. From these plots it would appear that the blade is experiencing some sort of mass loss at larger drop sizes.

American Institute of Aeronautics and Astronautics 


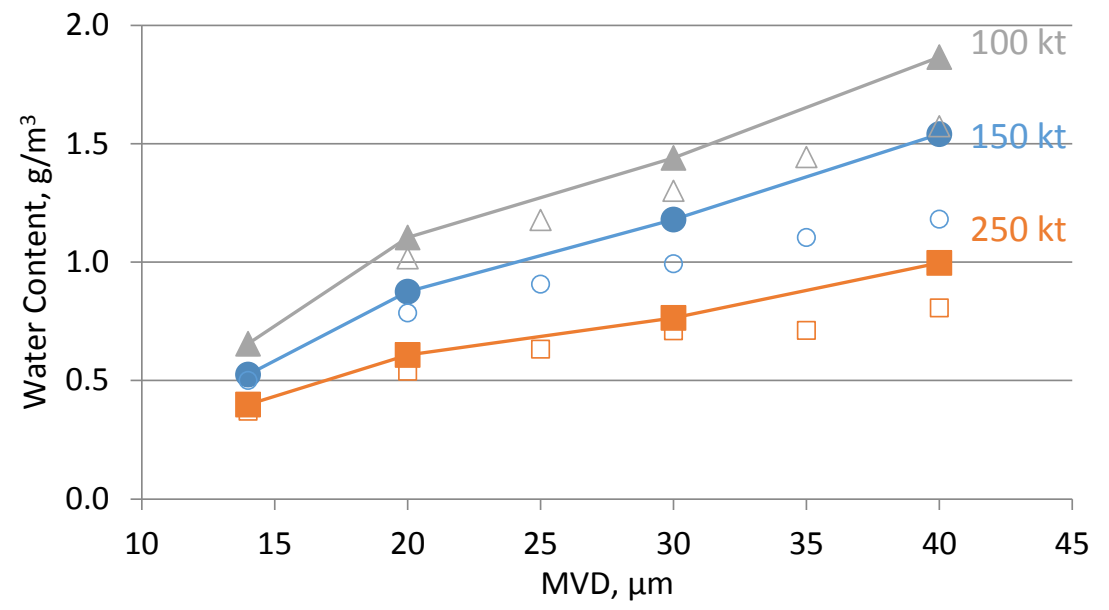

a) Nozzle air pressure $P_{\text {air }}=30$ psig

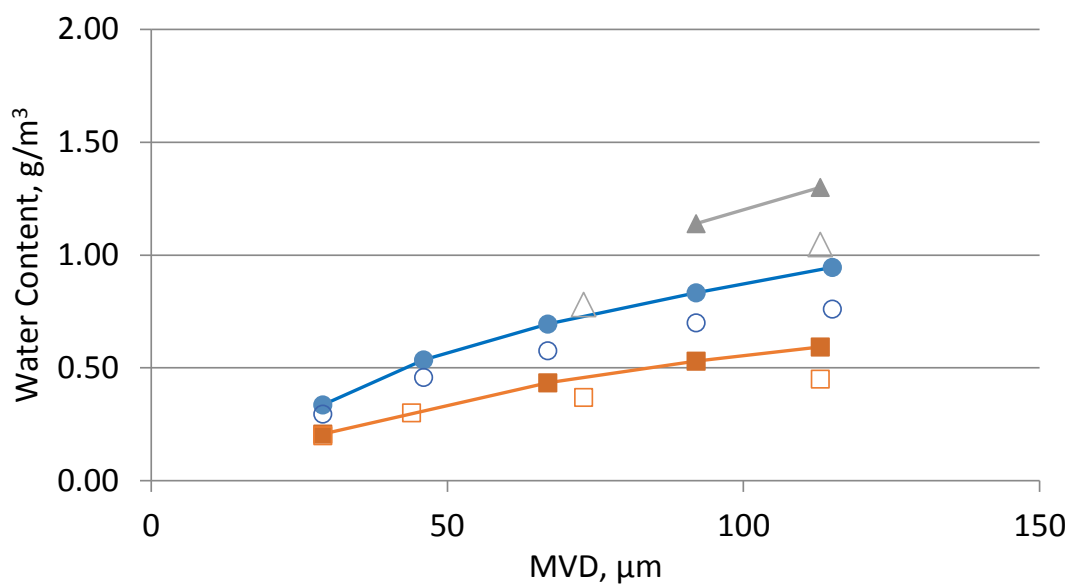

b) Nozzle air pressure $P_{\text {air }}=5$ psig

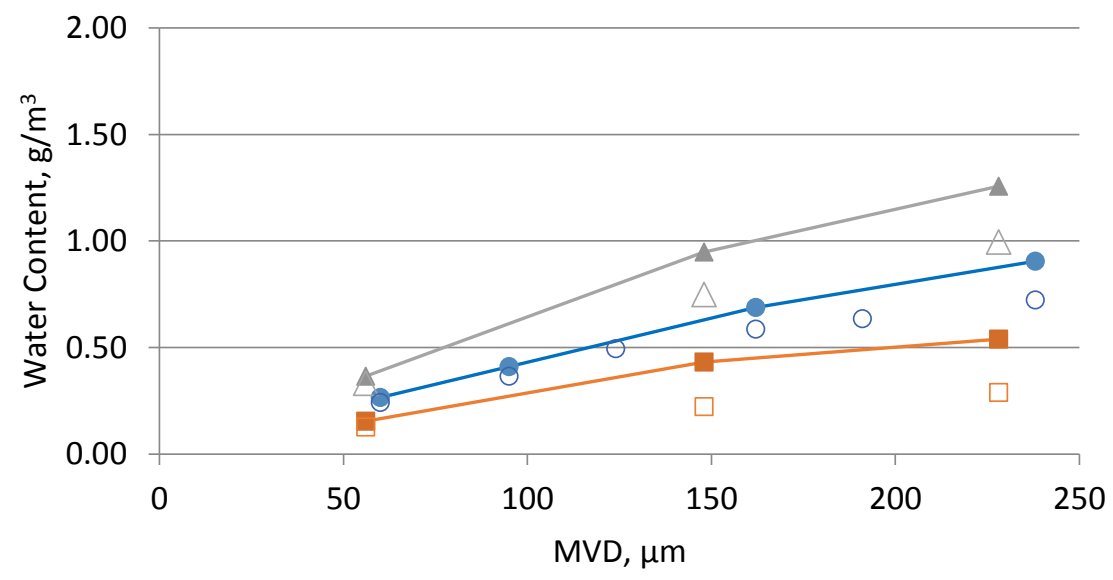

c) Nozzle air pressure $P_{\text {air }}=2$ psig

Figure 15. Comparison between the multi-wire (solid points with solid lines) and the blade (white-filled points with no lines) for different drop sizes, characterized by MVD. The different colors represent different airspeeds: grey is 100 knots, blue is 150 knots, and orange is 250 knots. Note the maximum value on the $x$-axis is different for each plot.

American Institute of Aeronautics and Astronautics 


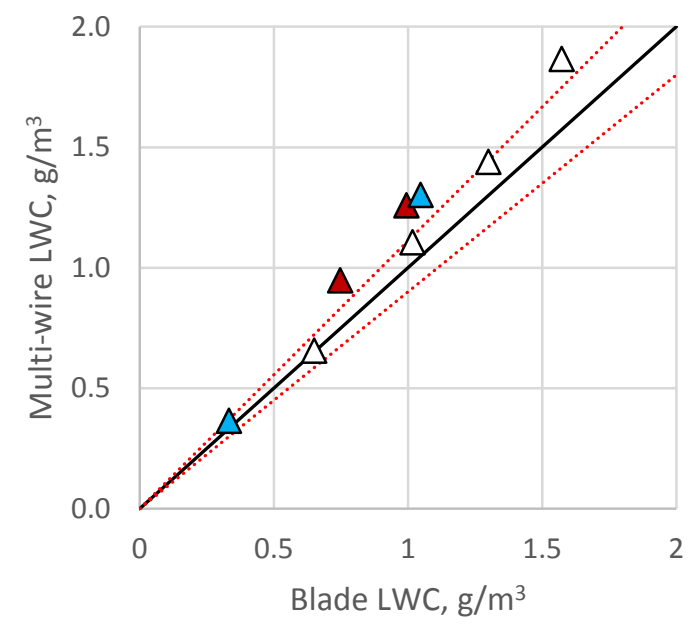

a) Test section airspeed $=100$ knots

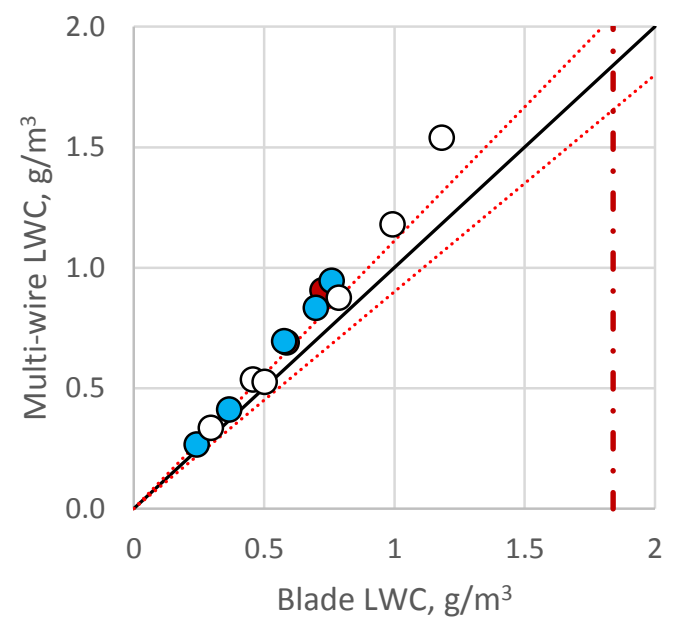

b) Test section airspeed $=150$ knots

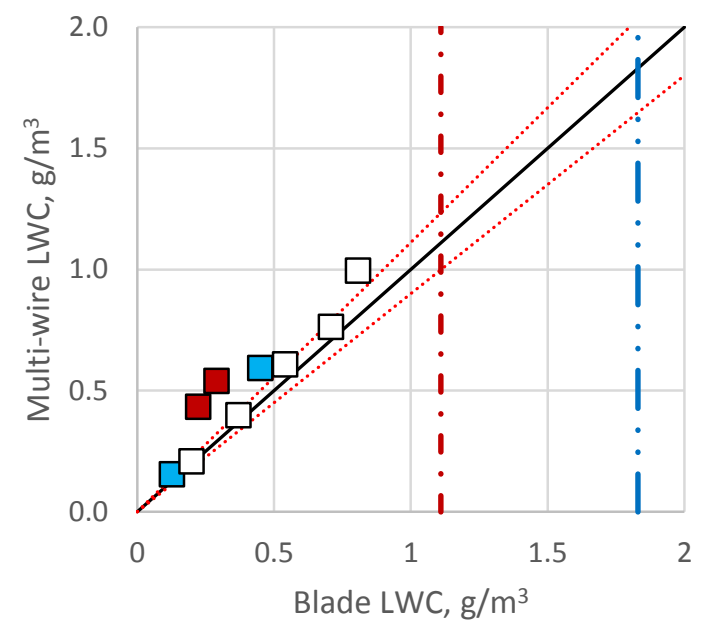

c) Test section airspeed $=250$ knots

Figure 16. TWC measured by the multi-wire compared to LWC measured by the blade for different drop sizes and airspeeds. The different colored symbols represent different MVD ranges: white is $0-50 \mu \mathrm{m}$, blue is $50-125 \mu \mathrm{m}$, and red is greater than $125 \mu \mathrm{m}$. The Ludlam limits for the blade are also shown, when the values are within the range plotted. The red dashed line is the Ludlam Limit assuming the blade temperature is equal to the total temperature, the blue dashed line is the Ludlam Limit assuming the blade temperature is equal to the static temperature. Each plot represents a different airspeed

It should be acknowledged that these plots do not indicate if the multi-wire probe may also be under-measuring at large drop sizes, as the hot-wire probes examined by Strapp, et. al., were shown to do ${ }^{12}$. (Note that those hot-wire instruments, except for the Nevzorov probe, had a cylindrical wire as the main sensing element, not a forward-facing half-pipe.) For the purpose of addressing this, refer to tests that were completed in the IRT in December 2014 with the Isokinetic Total Water Content Evaporator (IKP2) and the Multi-Element sensor ${ }^{6}$, shown in Fig. 17. The IKP2 was designed to measure the total water content of clouds for anticipated flights into deep convection where very high ice water contents are expected. The probe works by drawing the air and the water into the probe body isokinetically and evaporating all water content, measuring the total water vapor, and subtracting off the ambient water vapor. Among other things, these tests included an MVD-sweep that showed that as drop size increased, the IKP2 leveled off reading about $10 \%$ higher than IRT LWC Cal, while the multi-wire leveled off reading 4-5\% lower than the IRT LWC Cal (note this multi-wire data was not corrected for collision efficiency, which would cause the LWC at smaller drop sizes to be too low). What is most important to note is that these ratios are consistent even at very large drop 


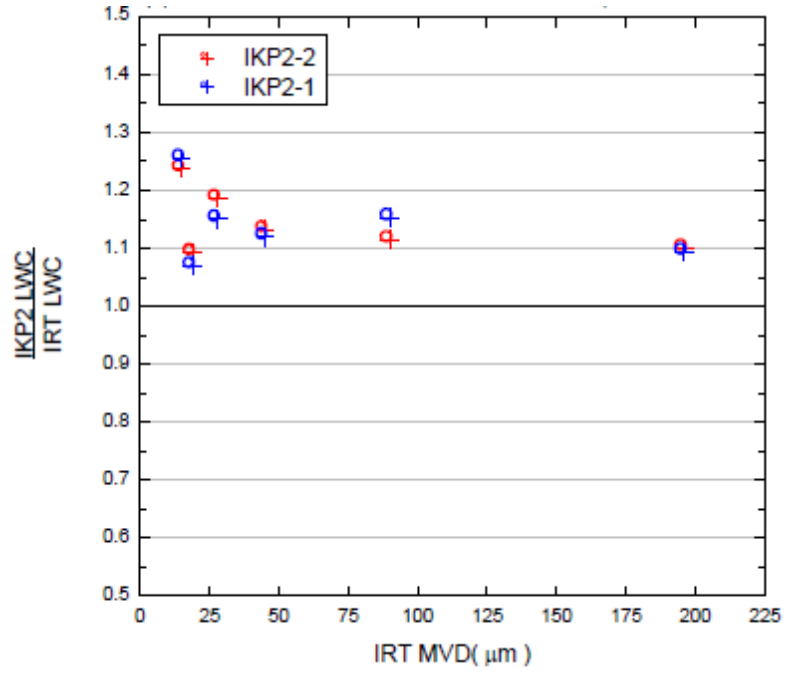

a) Ratio IKP2 to IRT Cal Test Point LWC, MVD Sweeps

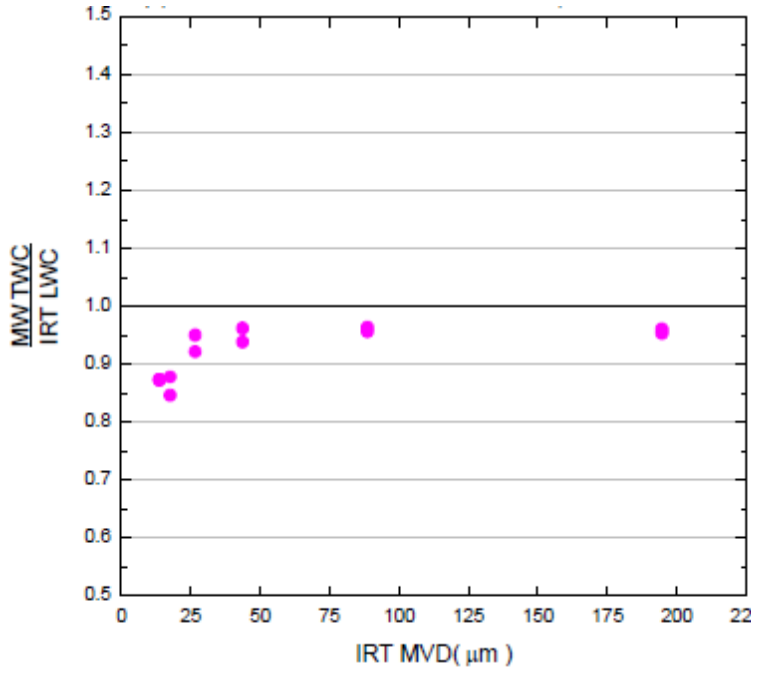

b) Ratio MW IRT Cal Test Point LWC, MVD Sweeps

Figure 17. MVD sweep results from Strapp \& Lillie's Dec 2014 tests in the IRT, testing the IKP2 alongside the multi-wire and comparing results from both to the IRT LWC Calibration'.

sizes, which suggests that any mass loss from the multi-wire is the same as any mass loss from the IKP. Addressing the $10 \%$ discrepancy between these two instruments is beyond the scope of this paper.

\section{Multi-Element sensor configurations}

A series of tests were conducted to determine the effect of sensor placement within the multi-wire shroud. Two sensor heads were tested, each with a different sensor configuration. The SN 2022 head (shown in Fig. 2b) has a forward-facing, 2.1-mm diameter half-pipe sensor in the center with a 2.1-mm hollow cylinder and a 0.5 -mm wire on the sides. The SN 2023 sensor has the $0.5-\mathrm{mm}$ wire in the center, with the 2.1-mm diameter half-pipe sensor and the 2.1-mm hollow cylinder on the sides. The 2023 sensor is a non-standard configuration, specifically ordered by the IRT from SEA to test the effect of sensor head placement. Tests were run with airspeeds ranging from 50 to 250 knots, LWC values between 0.2 and $4 \mathrm{~g} / \mathrm{m}^{3}$, and drop size distributions with MVD values between 14 and $230 \mu \mathrm{m}$. For this section of the report, data are examined for all three sensing elements. Results are shown in Fig. 18. In this figure, the TWC measured by forward-facing half-pipes in the different heads show good agreement, as do the water contents measured by from the $2-\mathrm{mm}$ hollow cylinder. The largest difference is seen in the $0.5-\mathrm{mm}$ wire element, which indicates that at high water contents, particularly for standard-nozzle conditions, the wire in the SN 2023 head reads notably higher than the wire in the SN 2022 head. One theory is that this is because when the 2mm-half-pipe element is in the center, aft of the other two sensors, the smaller drops in the cloud are diverted around the other two elements, and may be impinging on the $0.5-\mathrm{mm}$ wire, since it has a higher collision efficiency. Another theory is that water splashes off the two larger, upstream sensors and impinges as additional water content onto the 0.5 -mm sensor. Since the IRT uses only the measurements from the TWC element, these results were enough to confirm that the variations between the sensor heads were no more than what is seen from normal multi-wire and IRT repeatability.

American Institute of Aeronautics and Astronautics 


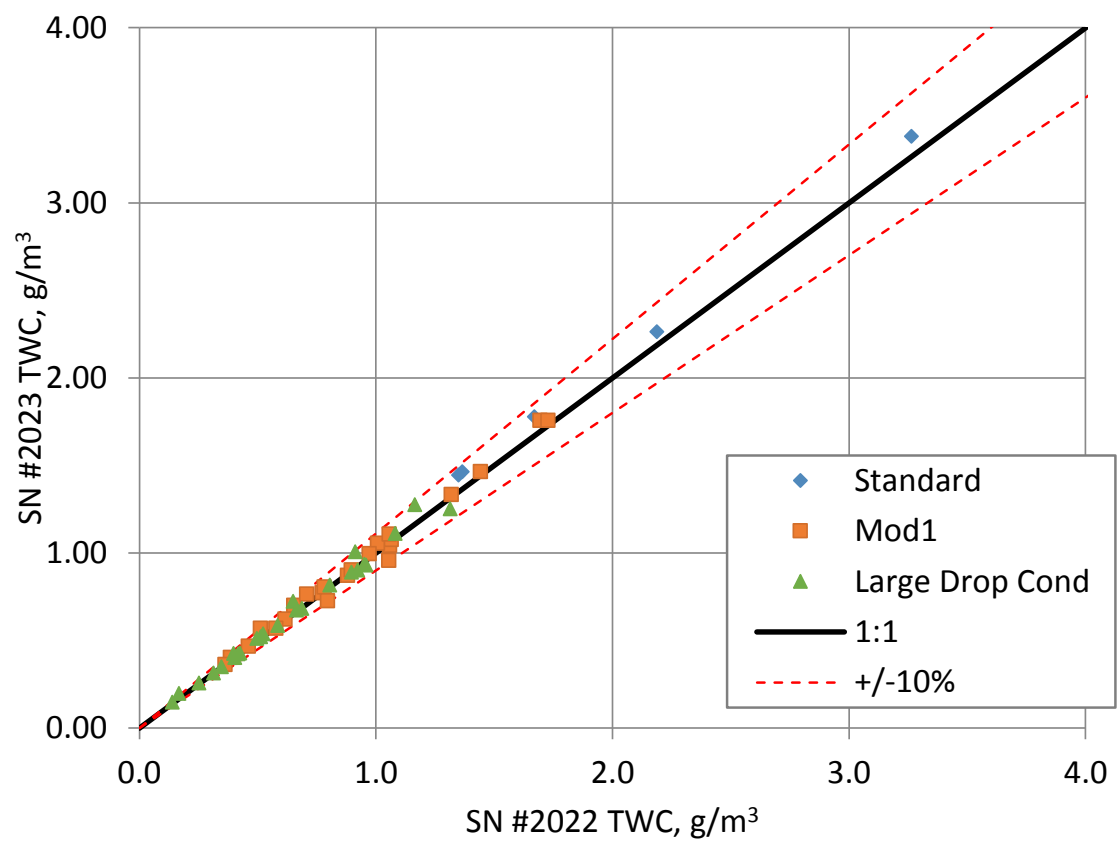

a) 2.1-mm diameter forward-facing half-pipe (TWC) element

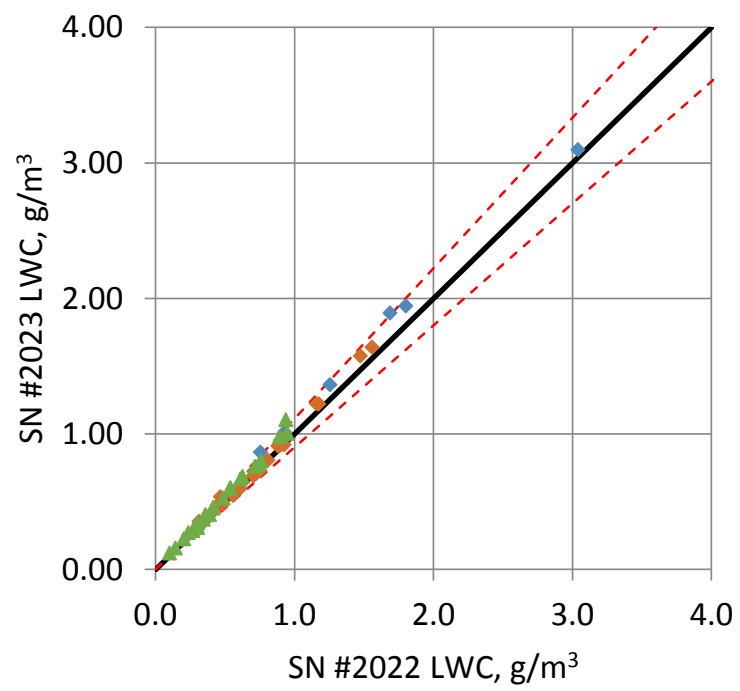

b) 2.1-mm diameter hollow cylinder

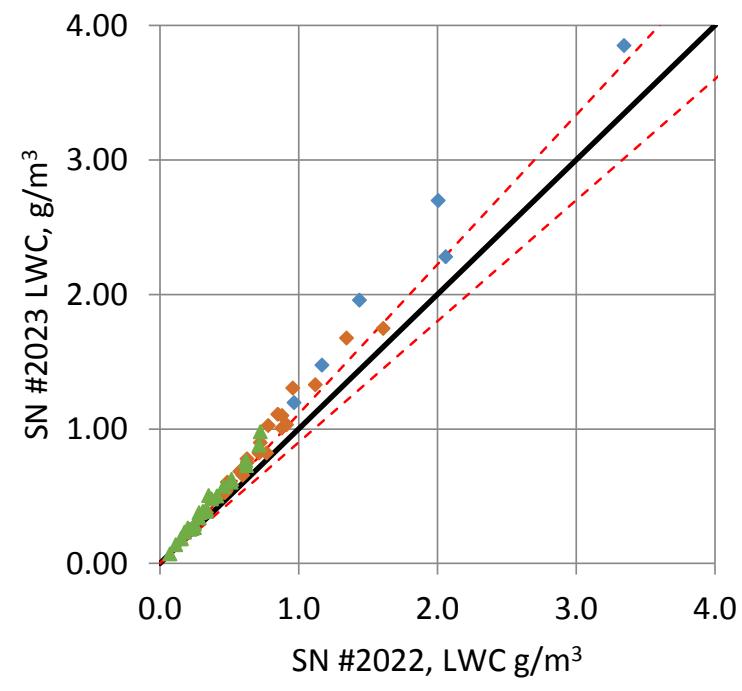

c) 0.5-mm diameter wire

Figure 18. Multi-wire sensor head comparisons. SN 2022 ( $x$-axis) has the half-pipe element in the center and the 2-mm hollow cylinder and $0.5-\mathrm{mm}$ wire on the sides, and is also shown in Fig. 2b. SN 2023 (y-axis) has the 0.5-mm wire element in the center and the forward facing half-pipe and 2-mm hollow cylinder on the sides.

\section{Conclusions}

Tests have been performed to assess the accuracy of the SEA Multi-Element sensor (multi-wire) for liquid water content measurements in the NASA Glenn Icing Research Tunnel by comparing its measurements with the blade.

To improve the data quality of the multi-wire, a few techniques have been implemented. A collision efficiency correction has been calculated using LEWICE3D, a particle trajectory code coupled with a three-dimensional flow

American Institute of Aeronautics and Astronautics 
field analysis ${ }^{4}$ as well as particle size distributions measured in the IRT. This collision efficiency correction is dependent on drop size and airspeed. This correction is only 1-2\% for 100- $\mu \mathrm{m}$ MVD distributions above 100 knots, but it can be greater than $15 \%$ at small drop sizes and low airspeeds. Also, a correction has been implemented for the step-increase in compensation wire power that coincides with the start of the spray. This correction averages around 1-2\% for high impingement rates. The percent impact can be higher when sensor power levels are low.

A few tests were also conducted to measure performance of the multi-wire compared to itself. Health-monitoring tests were conducted by taking dry (spray off) power readings at $+10{ }^{\circ} \mathrm{C}$ and airspeeds of 75,150 , and 250 knots. The standard deviation for the power readings of the TWC element over these health-monitoring checks was 1-3\% of the mean value. Secondly, repeat points were compared for the Mod1 and Standard nozzles over 2 years of test entries (5 entries), to measure the combined repeatability of the multi-wire and the IRT. For these conditions, the standard deviation of the TWC measurements was 2-3\% of the mean value. Lastly, comparisons were made of two different sensing element configurations: comparing the SN 2022 with a forward-facing half-pipe in the center, and the SN 2023 with a $0.5-\mathrm{mm}$ wire in the center. The water contents measured by the TWC elements for these two configurations showed about the same level of variation as the aforementioned multi-wire and IRT repeatability points, suggesting that the TWC element is not affected by a change in configuration. The $0.5-\mathrm{mm}$ wire, however, reads higher LWC values when it is mounted in the center, slightly aft of the other two sensors, particularly at higher LWC values. It has been theorized that this may be due to splashing from the other two larger sensors, or due to smaller drops being redirected around the two larger sensors and impinging on the smaller sensor that has a higher collision efficiency.

Most importantly, comparative tests were done between the multi-wire and the blade to determine its accuracy for calibrating the LWC of the IRT. Tests were completed to compare the two instruments with respect to LWC, airspeed, and drop size. The blade and the multi-wire were found to compare well for most Appendix C conditions, but at high impingement rates, when conditions approach the Ludlam Limit, the blade undermeasures. This is seen to be worse as drop size increases, which may suggest the blade is more prone to splashing.

Based on these analyses, the authors have concluded that the Multi-Element sensor is a better instrument than the Icing Blade for LWC measurements in the IRT. There is good agreement between the two instruments in the regions where agreement should be expected, and in high-impingement-rate conditions where there is disagreement, it can be expected that the Icing Blade is undermeasuring because of its Ludlam Limit. Similarly, for large-drop conditions, there is more reason to suspect mass loss or splashing from the Icing Blade than from the multi-wire, particularly because the multi-wire and IKP had similar response at large-drop conditions. The authors would like to acknowledge that they expect the multi-wire has a maximum LWC that the system is capable of measuring (possible pooling in the TWC element), as well as drop sizes that will be too large to be retained by the TWC element. However, there were no indications of these problems during testing in the IRT, even with LWC values in excess of $4.5 \mathrm{~g} / \mathrm{m}^{3}$ and drop size distributions with MVD values up to $230 \mu \mathrm{m}$ (maximum drop diameter of $1200 \mu \mathrm{m}$ ).

\section{Acknowledgments}

The authors would like to thank NASA's Aeronautics Test Program as well as NASA's Aeronautics Evaluation and Test Capabilities (AETC) Project for funding this effort. Many thanks are also due to all the IRT staff engineers and technicians who made these tests possible, though many faces have left and many new faces have arrived since 2009 when these tests began. Thanks also to Colin Bidwell, Dave Rigby, and Peter Struk for all their analysis and computing work to calculate the three-dimensional collision efficiencies on the multi-wire elements, and to Walter Strapp and Lyle Lilie, generating their report for NASA that included a plot comparing the IKP to the multi-wire over a range of MVD values.

\section{References}

${ }^{1}$ Steen, L.E., Ide, R.F., Van Zante, J.F., and Acosta, W. J., "NASA Glenn Icing Research Tunnel: 2014 and 2015 Cloud Calibration Procedure and Results," NASA/TM-2015-218758, May 2015.

${ }^{2}$ Pastor-Barsi, C., and Arrington, E. A., “Aero-Thermal Calibration of the NASA Glenn Icing Research Tunnel (2012 Tests)," NASA/CR-2013-217812, Mar 2013.

${ }^{3}$ Science Engineering Associates, “WCM-2000 Users' Guide," http://www.scieng.com/ Oct 6, 2010

${ }^{4}$ Rigby, D. L., Struk, P. M., and Bidwell, C., "Simulation of fluid flow and collection efficiency for an SEA multi-element probe," $6^{\text {th }}$ AIAA Atmospheric and Space Environments Conference, AIAA-2014-2752, 2014.

${ }^{5}$ Struk, P.M., NASA Glenn Research Center, personal communication.

${ }^{6}$ Strapp, J.W., Lilie, L., "Wind Tunnel Testing of the Second Generation Isokinetic Total Water Content Evaporator (IKP2); Testing of IKP2-2 and IKP2-1 at the NASA IRT, 15-17 Dec. 2014,” NASA Internal Report, March 2015

American Institute of Aeronautics and Astronautics 
${ }^{7}$ Struk, P. M., Rigby, D. L., and Venkataram, K., “A Thermal Analysis of a Hot-Wire Probe for Icing Applications," $6^{\text {th }}$ AIAA Atmospheric and Space Environments Conference, AIAA 2014-2331

${ }^{8}$ Frost, W., "Two-dimensional Particle Trajectory Computer Program," Interim Report for Contract NAS3-2248, Mar. 1982.

${ }^{9}$ Stallabrass, J. R., "An Appraisal of the Single Rotating Cylinder Method of Liquid Water Content Measurement," National Research Council Canada Internal Report, LTR-LT-92, 1978.

${ }^{10}$ Ludlam, F. H., "The Heat Economy of a Rimed Cylinder," Quarterly Journal of the Royal Meteorological Society, Vol. 77, 1951, pp. 663-666.

${ }^{11}$ CFR 14, Part 25, Appendix C, “Atmospheric Icing Conditions," http://www.ecfr.gov/cgi-bin/textidx?SID=259d868888112fec2583fa3951738ebd\&mc=true\&node=ap14.1.25_11801.c\&rgn=div9 accessed on 4/26/2016, updated annually.

${ }^{12}$ CFR 14, Part 25, Appendix O, "Supercooled Large Drop Icing Conditions," http://www.ecfr.gov/cgi-bin/textidx?SID=259d868888112fec2583fa3951738ebd\&mc=true\&node=ap14.1.25_11801.o\&rgn=div9 accessed on 4/26/2016, updated annually

${ }^{13}$ Strapp, J.W., Oldenburg, J., Ide, R., Lilie, L., Bacic, S., Vukovic, Z., Oleskiw, M., Miller, D., Emery, E., and Leone, G., "Wind Tunnel Measurements of the Response of Hot-Wire Liquid Water Content Instruments to Large Droplets," Journal of Atmospheric and Oceanic Technology, Vol. 20, 2003, pp. 791-806. 